\title{
Seismic Behavior of Special Truss Moment Frame with Double Hollow Structural Sections as Chord Members
}

\author{
Sanputt Simasathien ${ }^{1}$, Chatchai Jiansinlapadamrong ${ }^{2}$, and Shih-Ho Chao ${ }^{3}$
}

\begin{abstract}
Research work carried out on steel special truss moment frames (STMFs) with double-angle sections as chord members during the 1990s led to the formulation of design code provisions. Further research results using double-channel specimens resulted in a modified equation for the expected vertical shear strength of the central special segments, $V_{n e}$, and has been incorporated into the current AISC Seismic Provisions for Structural Steel Buildings. Double hollow structural sections (double-HSS) have the advantages of minimizing lateral torsional buckling and maximizing compactness in the flanges as compared to single HSS with the same flexural capacity. In this research, double-HSS members were proposed for the chord and web members of STMFs instead of double-angle, double-channel, or single-HSS. Double-HSS can effectively delay flange local buckling and enhance rotational ductility due to reduced width-to-thickness ratio $(b / t)$ without increasing the wall thickness of the members. A full-scale STMF subassemblage with double-HSS as truss members was tested under large displacement reversals to simulate a severe earthquake ground motion. Testing results indicate that using double-HSS truss members is a viable alternative for STMFs in high seismic regions. Plastic hinge models are also suggested for computer analysis and design of non-yielding members outside of the special segments.
\end{abstract}

${ }^{1} \mathrm{PhD}$, Dept. of Civil Engineering, University of Texas at Arlington, Arlington, TX 76019

${ }^{2}$ PhD Candidate, Dept. of Civil Engineering, University of Texas at Arlington, Arlington, TX 76019

${ }^{3}$ Associate Professor, Dept. of Civil Engineering, University of Texas at Arlington, Arlington, TX 76019, Email: shchao@uta.edu, Phone: +1 817272 2550, Fax: +1 8172722655 
KEYWORDS: Special truss moment frame, hollow structural sections, seismic design, steel 


\section{INTRODUCTION}

Research carried out in the 1990s on the seismic behavior of steel special truss moment frames (STMFs) using double-angle sections (Itani and Goel, 1991; Goel and Itani, 1991; Basha and Goel, 1994, 1995) led to the formulation of design code provisions incorporated into the American Institute of Steel Construction (AISC) Seismic Provisions for Structural Steel buildings in 1997 (Eq. 1) (AISC, 1997). One of the major advantages of using the STMF system is that truss girders can be economically used over longer spans due to the fact that higher overall structural stiffness can be achieved by using deeper girders. In addition, the open-webs can easily accommodate mechanical and electrical ductwork. As a consequence, this system offers a wide range of structural, architectural, and economical benefits because of its ability to achieve a large column-free floor.

STMFs dissipate earthquake energy through the ductile chord members of special segments located near the mid-span of the truss girders which act as a structural "fuse" as shown in Fig. 1(a). The members outside of the special segment are easily designed to remain elastic using the free-body diagram of the column tree subjected to design loading and expected vertical shear strength, $V_{n e}$, based on the capacity of the chord members in the special segment, seen in Fig. 1(b). The ductility of a truss system can also be improved by using dissipative energy devices, for example, using dampers at the ends of the bottom chords of the truss girders as shown by Longo et al. (2012).

STMFs located in high seismic zones call for truss member sections stronger than double-angle sections, which led to further research studies on STMFs with double-channel chord members and a revised equation in AISC Seismic Provisions for Structural Steel Buildings (AISC 341-10) 
in 2010 (Eq. 2) (Parra-Montesinos et. al, 2006; Chao and Goel, 2008a; AISC, 2010).

$$
\begin{aligned}
& V_{n e}=\frac{3.75 R_{y} M_{n c}}{L_{s}}+0.075 E I \frac{\left(L-L_{s}\right)}{L_{s}^{3}}+R_{y}\left(P_{n t}+0.3 P_{n c}\right) \sin \alpha \\
& V_{n e}=\frac{3.60 R_{y} M_{n c}}{L_{s}}+0.036 E I \frac{L}{L_{s}^{3}}+R_{y}\left(P_{n t}+0.3 P_{n c}\right) \sin \alpha
\end{aligned}
$$

where

$$
E=\text { modulus of elasticity of a chord member of the special segment }
$$

$I=$ moment of inertia of a chord member of the special segment

$L=$ length of the truss

$L_{s}=$ length of the special segment

$M_{n c}=$ nominal flexural strength of a chord member of the special segment

$P_{n t}=$ nominal tensile strength of a diagonal member of the special segment (if any)

$P_{n c}=$ nominal compressive strength of a diagonal member of the special

segment (if any)

$R_{y}=$ ratio of the expected yield stress to the specified minimum yield stress

$V_{n e}=$ expected vertical shear strength of the special segment

$\alpha=$ angle of diagonal members with the horizontal

As opposed to moment frames in which the plastic rotational demand in beams is close to the story drift ratio, the plastic rotational demand of the chord members in special segments of STMFs is significantly higher than the story drift ratio. The relationship between the story drift ratio and plastic hinge rotation of the chord members, as shown in Fig. 2, can be approximately 
estimated by Eq. 3 (Goel and Chao, 2008).

$$
\theta_{p}=\gamma+\beta \approx \frac{L}{L_{S}} \times(\text { storydrift ratio })-0.015(\text { rad } .)
$$

For a typical STMF with the ratio of truss girder span to the length of the special segment of 3.75 , the relationship between the story drift and the plastic rotation of the special segment chord members is shown in Table 1. It can be seen that the plastic rotational demand of the chord member in the special segment is as high as $6 \%$ and $10 \%$ at $2 \%$ and 3\% story drift ratios, respectively. These are beyond the typical rotational capacity of flexural members used in special moment frames.

Table 1. Relation between plastic rotation of chord members and story drift ratio of a typical STMF

\begin{tabular}{cc}
\hline Story drift ratio $(\%)$ & Plastic rotation of chord members $(\mathrm{rad})$ \\
\hline 0.50 & 0.00 \\
0.75 & 0.01 \\
1.00 & 0.02 \\
1.25 & 0.03 \\
1.50 & 0.04 \\
1.75 & 0.05 \\
2.00 & 0.06 \\
2.25 & 0.07 \\
2.50 & 0.08 \\
2.75 & 0.09 \\
3.00 & 0.10 \\
\hline
\end{tabular}

Hollow structural sections (HSS) are highly efficient structural sections used in resisting compression, torsion, and bending. Their high torsional rigidity generally eliminates lateraltorsional buckling (LTB), thereby eliminating the need for lateral bracing in beam-type members. Consequently, the plastic rotational capacity and strength degradation rate are primarily governed by flange local buckling (FLB) and web local buckling (WLB). Fadden and McCormick (2012) investigated the cyclic responses of single-HSS beam-column connections. 
The failure mode was primarily controlled by the effect of local buckling. They concluded that larger width-to-thickness ratios of the flanges $(b / t)$ led to a more significant decrease in the moment capacity as well as rotational capacity due to the importance of the flange in resisting cyclic bending. They suggested that width-to-thickness ratios of the flange $(b / t)$ and web $(h / t)$ below 25 and 40, respectively, are necessary to maintain $90 \%$ of the maximum moment strength at beam rotations of $0.04 \mathrm{rad}$.

In this research, double-HSS members were used for the chord and web members of STMFs instead of double-angle, double-channel, or single-HSS. The benefits of using double-HSS are as follows:

1. Effective delay of FLB and an enhanced rotational ductility is accomplished by reducing the width-to-thickness ratio $(b / t)$ without increasing the wall thickness of the members. A double-HSS flexural member can have similar moment capacity with an equivalent single-HSS beam, while having approximately half of the flange $b / t$ ratio.

2. According to AISC Seismic Provisions (2010), STMF chord members are required to be highly ductile or expected to undergo more than 0.04 rad of plastic rotation under the design earthquake. This translates to a stringent limiting width-to-thickness of walls of rectangular HSS of $0.55 \sqrt{E / F_{y}}$. Such requirement limits the single-HSS members that could be practically used for chord members of STMFs to satisfy both width-to-thickness ratio and strength requirements. Using the proposed double-HSS members increases the number of sections that can be selected for STMFs. Note that the $b / t$ and $h / t$ ratio is 13.9 for rectangular HSS with specified minimum yield stress of $315 \mathrm{MPa}$ (ASTM A500/A500M Gr. B). 
3. Double-HSS members provide stronger sections for STMFs in high seismic regions as compared to double-angle sections.

4. Double-HSS members utilize simple gusset plate connections with flare-bevel groove weld between the middle gusset plate and the double-HSS, one on each side of the gusset plate, without the inconvenience of making the necessary slots at both ends of a member in order to obtain welded gusset plate connections for single-HSS truss members.

\section{RESEARCH OBJECTIVES}

The goals of this research are:

1. To investigate the behavior of an STMF with double-HSS built-up chord and web members and to determine if the double-HSS built-up chord members can accommodate the large rotational demands in STMFs.

2. To verify the expected vertical shear strength of the special segment, $V_{n e}$, equations according to the latest AISC Seismic Provisions for Structural Steel Buildings (AISC 341-10).

Due to the lack of experimental results on STMF designed according to Eq. 2, the test results from this research could be used as its verification. In addition, previous tests on STMFs used to develop Eq. 1 were done on small-scale subassemblages with light double-angle sections.

3. To investigate the current requirements for the stability bracing of trusses with doubleHSS built-up chord members.

According to AISC 341-10, the required strength of the lateral brace, $P_{u}$, shall be 
$0.06 R_{y} F_{y} A_{f}$, where $R_{y}$ is the ratio of the expected yield stress to the specified minimum yield stress, $F_{y}$ is the specified minimum yield stress, and $A_{f}$ is the gross area of the flange (either top or bottom flange) of the special segment chord member. This requirement was based partly on what was used during the development of the first specifications for STMF in which specimens were constructed using double-angle sections as chord members in the original testing program (AISC, 2010). Since HSSs do not suffer from lateral-torsional buckling, this requirement might be over-conservative.

\section{EXPERIMENTAL PROGRAM}

\section{Component Test}

A component test was first conducted to investigate the cyclic behavior of the double-HSS (2HSS203.2 $\times 101.6 \times 12.7 ; b / t=5.6$ and $h / t=14.2)$ built-up member representing chord members in the special segment of an STMF as shown in Fig. 3. The member was welded to a $25.4 \mathrm{~mm}$ thick middle gusset plate which was welded to the column of a testing frame. The loading point represents the mid-length point of the chord members in the special segment of the STMF subassemblage in the full-scale experimental program. The displacement history planned for the component test specimen was developed based on a preliminary nonlinear pushover analysis of an STMF subassemblage similar to the one in the full-scale testing program. These member rotations correspond to story drift ratios according to the AISC 341-10 loading protocol for moment frames (AISC, 2010). It consists of six cycles at $0.0079,0.0105$, and 0.018 radian member rotation, four cycles at 0.0265 radian member rotation, and two cycles at 0.0435 , 0.0605, 0.0731, and 0.0911 radian member rotation. Fig. 4 shows hysteresis response of the 
double-HSS component and plastic hinge models used in nonlinear pushover analyses (discussed later) along with the nominal plastic moment capacity, $M_{p}$. It can be seen that the member exhibited a stable response without strength degradation up to member rotation of 0.06 radian. Afterward, strength maintained a slow degradation rate until the first cycle of 0.09 radian member rotation. As shown in Fig. 5, the local buckling in the double-HSS section was much less severe than that observed in the single-HSS section (Fadden and McCormick, 2012) that had similar strength as the double-HSS used in this study. This result proved that the double-HSS is capable of sustaining high rotational demand required by special segments in STMFs. The strength of the member drastically dropped due to fracture propagation in the following cycles and the test was terminated when the strength was below $M_{p}$ (Fig. 4). The member did not exhibit lateral torsional buckling (Fig. 5) as previously observed in the double-channel built-up members for STMF in a previous study (Parra-Montesinos et. al, 2006). The hysteresis response of the component test specimen (Fig. 4) was then used to analyze the behavior of the full-scale STMF subassemblage, as shown in Fig. 6, by a nonlinear pushover analysis.

\section{STMF Subassemblage Test}

AISC 341-10 Provisions state that the length-to-depth ratio of the special segment in an STMF shall neither exceed 1.5 nor be less than 0.67 (AISC, 2010). For STMFs of the same overall length and depth, the special segments with larger aspect ratios will reduce rotational demand of the chord members in a special segment (Eq. 3). The lower bound was suggested to limit the rotational demand of the chord members. On the other hand, a large length-to-depth ratio of the special segment can lead to the reduction of overall lateral elastic stiffness of an STMF. A full- 
scale STMF subassemblage specimen was designed to resemble the overall dimensions of a prototype building previously studied (Goel and Chao, 2008). For the specimens in this research, an aspect ratio of 2.5 was chosen for the subassemblage specimen to purposely violate AISC requirement. Preliminary nonlinear pushover analysis indicates that, with this aspect ratio, an STMF can maintain high lateral stiffness while the rotational demand of the chord reduces to the level that a ductile member is able to sustain.

The specimen design started by selecting double-HSS (2HSS203.2×101.6×12.7) as the chord members. The design of elements outside of the special segments, including truss members, columns, and connections, was based on the capacity design approach using a column-tree method (Chao and Goel, 2008b) such that those elements would remain elastic when the maximum vertical shear force, $V_{n e}$, is reached in the middle of the truss girder.

\section{Description of Test Specimen}

The full-scale STMF subassemblage specimen was constructed with double-HSS built-up sections (2HSS203.2×101.6×12.7) as chord members. The vertical members at the ends of special segment were the same sections as the chord members as suggested by Basha and Goel (1994). The vertical and diagonal members outside of the special segment were also double-HSS built-up sections $(2 \mathrm{HSS} 127 \times 127 \times 9.5)$. The overall length (center-to-center of the columns) was $9695 \mathrm{~mm}$. The length of special segment was $3025 \mathrm{~mm}$ and the depth of the truss was $1220 \mathrm{~mm}$. Fig. 6 shows the overall dimensions of the subassemblage specimen. The details at the end of vertical and chord member in the special segment (shown in Fig. 7) are as follows:

1. Connections at the end of the vertical members at the ends of the special segment were 
not butted up against the chord members in order to allow large inelastic strains to freely spread. This was done to prevent any restraint at the plastic hinging region which reduces the rotational capacity of the chord members.

2. Flare-bevel groove welds were used between truss members and gusset plates throughout the truss.

\section{Test Setup and procedure}

The test setup at the University of Minnesota's Multi-Axial Subassemblage Testing (MAST) Laboratory is shown in Fig. 8. Stability bracing of the truss was provided, as required by AISC 341-10, through the truss lateral support system. However, it was located slightly outside of the special segment so that it would not obstruct the movement of the specimen when local buckling initiated at the plastic hinges at large story drift ratios. Stability bracing of the truss-to-column connection was provided as per AISC 341-10 around both columns. Pin connections were used at the top and the bottom of the columns to simulate the inflection points of columns in multistory STMF structures.

The specimen was cyclically loaded according to a loading protocol similar to the AISC 341-10 loading sequence for beam-to-column connections of moment frames (AISC 341-10) by means of lateral force applied by the crosshead through a load transfer beam. Graphical representation of the story drift ratio history is shown in Fig. 9. Prior to applying the prescribed displacement history, a small displacement of $5 \mathrm{~mm}$ was applied in both directions to verify that all instruments were working properly. 


\section{EXPERIMENTAL TEST RESULTS}

Fig. 10 shows the specimen (special segment) at the end of different story drift ratio cycles. The behavior of the specimen was stable and ductile up to approximately $3 \%$ story drift ratio. Plastic hinges formed at the expected locations (the ends of the chord members in the special segment) without any yielding in the members outside of the special segment. The lateral force at the crosshead versus drift responses of the specimens is close to the anticipated lateral force obtained from revised pushover analyses as shown in Fig. 11. The corresponding equivalent shear force at the center of the special segment was calculated by using the static equilibrium and is shown in Fig. 12.

Table 2 summarizes the calculated values of $V_{n e}$ according to AISC and the equivalent shear force computed from the equilibrium condition.

Table 2. Calculated $V_{n e}$ and equivalent vertical shear force from test results

Calculated $V_{n e}(\mathrm{kN}) \quad$ Equivalent vertical shear force from test results $(\mathrm{kN})$

\begin{tabular}{cccc}
\hline $\begin{array}{c}\text { AISC 341-05 } \\
\text { (Eq. 1) }\end{array}$ & $\begin{array}{c}\text { AISC 341-10 } \\
\text { (Eq. 2) }\end{array}$ & Positive drift & Negative drift \\
\hline 641 & 558 & 645 & 609 \\
\hline
\end{tabular}

\section{Behavior during tests and at failure}

As shown in Fig. 11, the specimen behaved elastically up to nearly $0.75 \%$ story drift ratio and exhibited stable and ductile behavior up to the first cycle of the $3 \%$ story drift ratio. Strength increased while stiffness gradually decreased from $1 \%$ to $3 \%$ story drift ratio. At the end of the first cycle of the $2 \%$ story drift ratio, small fractures began to appear at the end of the welds connecting the chord members to the gusset plates at the ends of the special segment; however, they did not affect the overall strength of the specimen. Fractures gradually propagated into the 
flanges of the chord members at the first cycle of 3\% story drift ratio. After the first peak at $3 \%$ story drift ratio, large cracks formed on the tension side at the ends of chord members in the special segment and the specimen could not attain the same magnitude of lateral force when it underwent the peak displacement on the opposite direction. The strength dropped slightly during the second cycle of $3 \%$ story drift ratio. Strength of the specimen started to degrade significantly at the first negative cycle of $4 \%$ story drift ratio, at which time the majority of the chord members in the special segment were torn and the capacity of the specimen drastically dropped to approximately $30 \%$ of the peak strength. In the second cycle of $4 \%$ story drift ratio, lateral force dropped to about $16 \%$ of the peak strength, and the experiment was terminated. Fig. 13 shows the failure at the end of the chord members in the special segment of the subassemblage compared to the component test specimen. In both case, the failure was due to fracturing after low-cycle fatigue accompanied by slight necking of the section. No local buckling and lateraltorsional buckling was observed.

\section{DISCUSSION}

\section{Requirement for the stability bracing of trusses}

The lateral bracing system consisting of steel plates and threaded rods was instrumented with strain gauges to obtain the lateral forces (in transverse direction to the truss) at each corner of the special segments (Fig. 14). The same rods were later tested to determine the force versus deformation relation (Fig. 15). Lateral forces were then calculated based on the strain gauge response using a set of calibrated data from gauges on threaded rods. Examples of the strain response from individual thread rods are shown in Fig. 16. It can be seen that the responses are 
significantly different from the theoretical values obtained by using the nominal area $\left(284 \mathrm{~mm}^{2}\right.$ for a 19-mm diameter threaded rod used in this experimental program). Fig. 17(a) shows the maximum Error! Reference source not found. lateral bracing forces at different targeted story drift ratios. The lateral bracing force responses at each corner of the special segment are shown in Fig. 17(b). The lateral bracing force gradually increased from $6.3 \mathrm{kN}$ (1.4 kips) during 0.375\% story drift ratio cycles to $9.9 \mathrm{kN}$ (2.2 kips) at the end of $1.5 \%$ story drift ratio cycles. It increased to $25.4 \mathrm{kN}$ (5.7 kips) at the end of the first cycle of $2 \%$ story drift ratio and reached the maximum value of $51.2 \mathrm{kN}$ (11.5 kips) during the second cycle of $4 \%$ story drift ratio. The maximum bracing forces typically occurred at the peak drift ratios, except when the drift ratios went beyond approximately 3\% story drift. By this time, significant damage had occurred in the special segment causing the specimen to lose its lateral stability. Analytical studies indicated that, for typical STMF systems, the mean story drift ratios at design basis earthquakes (DBE) (10\% probability of exceedance in 50 years) and maximum considered earthquakes (MCE) (2\% probability of exceedance in 50 years) are approximately $1.5 \%$ and $2.5 \%$, respectively (Chao and Goel, 2008b). It can be seen that the highest observed lateral bracing forces $(30.3 \mathrm{kN})$ at $3 \%$ story drift ratio are less than $50 \%$ of that required by AISC $341-10$ 's requirement $(63.9 \mathrm{kN})$. It is worth mentioning that for STMFs using double-channel as chord members at the peak strength ( $2 \%$ story drift ratio), the maximum lateral force had already reached $98 \%$ of the AISC required strength of the lateral brace (Simasathien, 2016). This indicates that the current AISC requirement can be reduced for STMF with double-HSS built-up sections as chord members. This is due to the fact that HSSs do not suffer from LTB and are more stable in the out-of-plane direction. Eq. 4a and Eq. $4 \mathrm{~b}$ are suggested for the required strength of the lateral brace, $P_{u}$, for 
STMF constructed with double-HSS as chord members for the load and resistance factor design (LRFD) method and allowable strength design (ASD) method, respectively.

$$
\begin{aligned}
P_{u} & =0.04 R_{y} F_{y} A_{f}(L R F D) \\
P_{u} & =(0.04 / 1.5) R_{y} F_{y} A_{f}(A S D)
\end{aligned}
$$

\section{Discussion of predictive formula and strain gauge data}

The peak equivalent vertical shear forces obtained from test results (Fig. 12) were close to the expected vertical shear strength, $V_{n e}$, predicted by AISC 341-05 (Eq. 1), but higher than that of AISC 341-10 (Eq. 2) by approximately 16\%. This seems to indicate that AISC 341-10's equation underestimates the vertical shear strength of STMFs. However, further investigation indicates that the majority of the members outside of the special segment had strains much lower than the yield strain of steel, $\varepsilon_{y}$ (see detailed strain analysis in next paragraph). This suggests that the AISC 341-10's equation (Eq. 2) still gives a safe design.

A portion of the HSS used in the chord members of the full-scale STMF specimen was cut off and set aside for the tensile test in order to obtain the material properties. Fig. 18 shows the location of the cut locations for the tensile test coupon specimens. The average yielding strength of the section cut from the flange area was $450 \mathrm{MPa}$, which is significantly higher than the specified yield stress of $315 \mathrm{MPa}$. The average yielding strength of the web area was $410 \mathrm{MPa}$.

Fig. 19 shows the results from the tensile tests using the average strain of the gauge length (50 $\mathrm{mm}$ ) obtained from a digital image correlation (DIC) measurement in accordance with ASTM E8/E8M (ASTM, 2015) and compared to conventional strain gauges placed at the center and at both ends of the gauge length. The average yielding strength from the tensile test could be used to find yielding moment which for a plastic hinge model in nonlinear analysis of STMFs 
(discussed later).

Fig. 20 shows the maximum strain levels observed during the test on members outside of the special segment. Fig. 21 shows the hysteretic strain response of strain gauges that recorded the maximum strain level in the member and gusset plate located outside of the special segment. The maximum strain occurred in members outside of the special segment was observed at $84 \%$ of the yield strain, assuming 2000 micro-strain $(0.002 \mathrm{~mm} / \mathrm{mm})$ as the yielding point. This only occurred at one particular location (Strain Gauge M4-1-2) as shown in Fig. 20. These data indicate that the predicted $V_{n e}$ value from the AISC 341-10 is still conservative. For the vertical members at the ends of the special segment, the highest strain utilization was observed at $85 \%$ of the yield strain (Fig. 22).

Fig. 23 shows that the first yielding of the chord member (at top flange) occurred at the story drift ratio slightly higher than $0.5 \%$. Strain profiles along the length of the top chord members at the end of the special segment indicate that the length of the plastic hinge was approximately 650 $\mathrm{mm}$ (about three times the depth of the member) assuming the plastic hinge starts at the end of weld between the members and the gusset plate (location of strain gauge S1 as shown in Fig. 23) at the story drift ratio of $3.0 \%$.

\section{Recommended design approach for non-yielding members outside of the special segment}

While AISC 341-10 (AISC, 2010) suggests a $V_{n e}$ equation for the design of members outside of the special segment, it may not be the most direct and easy way to design those non-yielding members when the entire 3D building model is created by a computer software program. A more straightforward design could be done by directly modeling the plastic hinge properties of the chord members, then determining the forces in the non-yielding members by a pushover analysis 
of the 3D model. The following design procedure and information is recommended:

1. Use the generalized moment-rotation relationship for plastic hinges in the chord member as shown in Fig. 24. The second row in Table 3 summarizes the values used for the plastic hinge properties of the pushover analyses in this study. These values are obtained from the component test result (Fig. 4). When component testing results are not available, the third row in Table 3 provides recommended values for STMFs with double-HSS built-up sections as chord members. As shown in Fig. 11, the recommended values give a reasonable force-displacement envelope (red line) as compared to the cyclic testing of the full-scale specimen.

2. Carry out a pushover analysis until the story drift ratio reaches at least $1.5 \%$. At that time, the maximum shear at the middle of the special segment reaches a value slightly greater than AISC 341-10's $V_{n e}$ value (Fig. 12). Then use the forces in the non-yielding members to carry out the usual elastic design for these members.

Table 3. Plastic hinge modeling parameters

\begin{tabular}{|c|c|c|c|c|c|c|c|}
\hline & $\begin{array}{l}\mathrm{M}_{\mathrm{p}, \exp } \mathrm{kN}-\mathrm{m} \\
\text { (kip-in.) }\end{array}$ & $\begin{array}{c}\mathrm{M}_{\mathrm{u}}, \mathrm{kN}-\mathrm{m} \\
\text { (kip-in.) }\end{array}$ & $\begin{array}{c}\mathrm{M}_{\mathrm{r}}, \mathrm{kN}-\mathrm{m} \\
\text { (kip-in.) }\end{array}$ & $\begin{array}{c}\mathrm{D}_{\mathrm{y}} \\
(\mathrm{rad})\end{array}$ & $\begin{array}{c}\mathrm{D}_{\mathrm{u}} \\
(\mathrm{rad})\end{array}$ & $\begin{array}{c}\mathrm{D}_{1} \\
(\mathrm{rad})\end{array}$ & $\begin{array}{c}\mathrm{D}_{\mathrm{r}} \\
(\mathrm{rad})\end{array}$ \\
\hline $\begin{array}{l}\text { Results from } \\
\text { component test } \\
((2 \mathrm{HSS} 203.2 \times \\
101.6 \times 12.7)\end{array}$ & $380(3340)$ & $\begin{array}{c}450 \\
(3975)\end{array}$ & $45(400)$ & 0.023 & 0.043 & 0.073 & 0.091 \\
\hline $\begin{array}{l}\text { Recommended } \\
\text { values for } \\
\text { double-HSS } \\
\text { built-up } \\
\text { sections }\end{array}$ & $R_{y} F_{y} Z$ & $1.3 M_{p, \exp }$ & $0.1 M_{u}$ & $\frac{M_{p} L_{s}}{3.8 E I}$ & 0.04 & 0.07 & 0.09 \\
\hline Alternatives & $F_{y}$,actual ${ }^{1} \mathrm{Z}$ & $\begin{array}{c}504^{2} \\
(4458)\end{array}$ & - & - & - & - & - \\
\hline
\end{tabular}

\footnotetext{
${ }^{1}$ From average yield strength of flange and web from coupon testing

${ }^{2}$ Result from section analysis by program XTRACT
} 
Alternatively, if material test results are provided (such those shown in Fig. 19), the expected plastic moment capacity, $M_{p, \exp }$, and ultimate moment capacity, $M_{u}$, could be found by using the average yield strength of the flange and web from coupon testing times plastic modulus. As for $M_{u}$, a computer program such as XTRACT (XTRACT 2006) could be used to analyze moment capacity of a section given the material models of the cross section. In XTRACT, three models of the steel material are available: bilinear with strain hardening model, Menegotto Pinto model, and user-defined model. Fig. 25(a) shows material models in XTRACT that were used to match the material test results from the coupon specimens cut from flange and web of the component test specimen. The cross section of the HSS in the XTRACT model was drawn without corner radius resulted in $12.9 \%$ and $16.0 \%$ increases in cross sectional area and plastic modulus respectively. This leads to slightly conservative design of the non-yielding members. Fig. 25(b) shows moment vs. curvature analyzed by the XTRACT. It can be seen in Table 3 that the ultimate moment capacity from the program is $12.2 \%$ higher than the test results.

One can also use other mathematical models to estimate the ultimate flexural strength of the HSS sections. Güneyisi et al. (2013) proposed a formulation to estimate the overstrength factor based on geometric properties of the sections, mechanical properties of material, as well as shear span of the beams. In their study, overstrength factor is defined as $M_{u} / M_{p}$, where $M_{p}$ is the theoretical plastic moment. An estimation of rotational capacity of cold-formed HSSs was studied by D'Aniello et al. (2014) based on neural network and genetic expression programming. The proposed formulations of rotational capacity, though require soft computation, were able to use to predict rotational capacity of HSSs by using both geometrical and mechanical properties such as width, depth, wall thickness, inside corner radius, yield stress, ratio of modulus of elasticity to 
hardening modulus, and ratio of the strain at onset of strain hardening to yield strain,

\section{SUMMARY AND CONCLUSIONS}

This paper presents test results of an STMF subassemblage specimen constructed with doubleHSS built-up chord members. Double-HSS members' high torsional rigidity eliminates lateraltorsional buckling, thereby eliminating the need for lateral bracing in beam-type members. They also effectively delay flange local buckling thereby enhancing rotational ductility due to the reduced width-to-thickness ratio $(b / t)$ as compared to a single-HSS with the same flexural capacity. Only a simple connection detail utilizing gusset plate with direct welding between the gusset plate and the double-HSS is needed for the fabrication. The following conclusions can be drawn from the results of this study:

1. A full-scale STMF subassemblage test indicated that double-HSS members can be a viable option for the chord members in the special segments. They provide high rotational capacity up to nearly 0.09 radian before significant degradation occurs. This high rotational capacity is particularly critical for STMFs due to the high rotational demand in the special segments.

2. Although the current $V_{n e}$ equation (AISC 341-10) slightly underestimates the maximum expected shear strength of the STMF subassemblage using double-HSS chord members, test results show that members outside of the special segment did not experience any yielding even when the chord members in the special segment were completely fractured. Therefore the current $V_{n e}$ equation for STMFs is still valid.

3. The observed yield drift ratio (approximately $0.75 \%$ ) of the full-scale specimen is nearly the same with the STMF with a special segment having a length-to-depth ratio of 2.0 
(Chao and Goel, 2008b). Therefore, the upper limit for the length-to-depth ratio of any panel in the special segment could be increased to 2.5 without affecting the elastic lateral stiffness of STMFs.

4. The current requirement for the stability bracing of trusses (AISC 341-10, Eq. E4-1a and E4-1b) can be safely reduced for STMFs with double-HSS built-up chord members. Recommended equations (Eqs. $4 \mathrm{a}$ and $4 \mathrm{~b}$ in this paper) for the required strength of the lateral brace for STMF constructed with double-HSS are proposed.

5. While the $V_{n e}$ equation specified in AISC 341 is more convenient when a "column-tree" procedure (Chao and Goel, 2008b) is used to design non-yielding members outside of the special segments, this paper suggests a moment-rotation model for the plastic hinges at chord members as well as a pushover analysis procedure to design the non-yielding members outside of the special segments. The suggested method can be more convenient when a 3D building model is built by computer which is typically done in modern design; hence, one does not have to carry out an additional column-tree analysis.

\section{ACKNOWLEDGEMENTS}

This research was supported by the U.S. National Science Foundation's George E. Brown Jr. Network for Earthquake Engineering Simulation (NEES) program under award number CMMI0936563 and the American Institute of Steel Construction. The opinions and views expressed in this paper are solely those of the authors and do not reflect those of the sponsors. The authors would like to thank NEES Program Director Dr. Joy M. Pauschke for her support. The authors would also like to thank Professor Carol Shield, Paul Bergson, Rachel Gaulke, Michael 
Boldischar, Samantha Thomas, Christopher Bruhn, and Lauren Snyder at the University of

Minnesota's Multi-Axial Subassemblage Testing Laboratory for their assistance.

\section{REFERENCES}

1. AISC (American Institute of Steel Construction). (1997). "Seismic provisions for structural steel buildings." ANSI/AISC 341-97, Chicago, IL.

2. AISC (American Institute of Steel Construction). (2010). "Specification for structural steel buildings." ANSI/AISC 360-10, Chicago, IL.

3. ASTM International (2015). "Standard test methods for tension testing of metallic materials." ASTM E8/E8M-15a, West Conshohocken, PA.

4. Basha, H. S., and Goel, S. C. (1994). "Seismic Resistant Truss Moment Frames with Ductile Vierendeel Segment." Rep. UMCEE 94-29, Dept. of Civil Engineering, Univ. of Michigan, Ann Arbor, MI.

5. Basha, H. S., and Goel, S. C. (1995). "Special truss moment frames with Vierendeel middle panel." Eng. Struct., 17(5), 352-358.

6. Chao, S-. H., and Goel, S. C. (2008a). "A modified equation for expected maximum shear strength of the special segment for design of special truss moment frames." Eng. J., 45(2), 117-125.

7. Chao, S.-H., and Goel, S. C. (2008b), "Performance-based plastic design of special truss moment frames." Eng. J., 45(2), 127-150.

8. D'Aniello, M., Güneyisi, E. M., Landolfo, R., and Mermerdaş, K. (2014). "Analytical prediction of available rotation capacity of cold-formed rectangular and square hollow section beams." Thin-Walled Struct., 77(2014), 141-152.

9. Fadden, M., and McCormick, J. (2012). "Cyclic quasi-static testing of hollow structural section beam members." J. Struct. Eng., 135(5), 561-570.

10. Goel, S. C., and Chao, S-. H. (2008). "Performance-based plastic design: Earthquakeresistant steel structures." ICC, County Club Hills, IL.

11. Goel, S. C., and Itani A. M. (1991). "Seismic resistant special truss moment frames." $J$. Struct. Eng., 120(6), 1781-1797.

12. Güneyisi, E. M., D'Aniello, M., Landolfo, R., and Mermerdaş, K. (2013). "A novel formulation of the flexural overstrength factor for steel beams." J. Constr. Steel Res., 90(2013), 60-71.

13. Itani, A. M., and Goel, S. C. (1991). Earthquake Resistant Design of Open Web Framing Systems. University of Michigan, Ann Arbor, MI.

14. Longo, A., Montuori, R., and Piluso, V. (2012). "Failure mode control and seismic response of dissipative truss moment frames." J. Struct. Eng., 138(11), 1388-1397.

15. Parra-Montesinos, G., Goel, S.C., and Kim, K-. Y. (2006). "Behavior of steel double channel built-up chords of special truss moment frames under reversed cyclic bending." J. Struct. Eng., 132(9), 1343-1351.

16. Simasathien, S. (2016). "Cyclic Loading Performance of Special Truss Moment Frames 
and Modified Structural Layouts for Staggered Truss Framing System for Seismically Active Areas." Ph.D. thesis, Dept. of Civil Engineering, Univ. of Texas at Arlington, Arlington, TX.

17. XTRACT [computer program]. Version 3.0.5. Sacramento, CA.: Imbsen Software Systems; 2006. 


\section{NOTATION}

The following symbols are used in this paper:

$\alpha=$ angle of diagonal members with the horizontal;

$\beta=$ angle of vertical members at the ends of the special segment with the vertical;

$\gamma=$ angle of chord members with the horizontal;

$\theta_{p}=$ plastic hinge rotation of chord members;

$b=$ width of compression element;

$A_{f}=$ gross area of the flange;

$D_{l}=$ member rotation corresponding to the beginning of strength loss;

$D_{r}=$ member rotation corresponding to the end of strength loss;

$D_{y}=$ member rotation corresponding to expected flexural strength;

$D_{u}=$ member rotation corresponding to required flexural strength;

$E=$ modulus of elasticity of steel;

$F_{y}=$ specified minimum yield stress of the type of steel to be used;

$F_{y, \text { actual }}=$ actual yield stress of steel from a coupon test;

$h=$ the clear distance between the flanges less the inside corner radius on each side;

$I=$ moment of inertia of a chord member of the special segment;

$L=$ span length of truss;

$L_{s}=$ length of special segment;

$M_{n c}=$ nominal flexural strength of a chord member of the special segment;

$M_{p}=$ nominal plastic flexural strength;

$M_{p, \exp }=$ expected plastic flexural strength;

$M_{r}=$ residue flexural strength;

$M_{u}=$ required flexural strength, using LRFD load combinations;

$P_{n c}=$ nominal compressive strength of the chord member at the ends;

$P_{n t}=$ nominal axial tensile strength of a diagonal members of the special segment;

$P_{u}=$ required axial strength, using LRFD load combinations;

$R_{y}=$ ratio of the expected yield stress to the specified minimum yield stress, $\mathrm{F}_{\mathrm{y}}$;

$t=$ thickness of element;

$V_{n e}=$ expected vertical shear strength of the special segment;

$Z=$ plastic section modulus of a member. 


\section{LIST OF FIGURES}

Fig. 1. STMF: (a) Yielding mechanism adapted from Goel and Chao (2008), (b) free-body diagram of column tree and associated truss girder portions adapted from Goel and Chao (2008)

Fig. 2. Deformed shape of STMF

Fig. 3. Component test specimen representing chord members in the special segment (unit: $\mathrm{mm}$ )

Fig. 4. Hysteresis response of component specimen and nonlinear models of plastic hinge

Notes: ${ }^{1}$ Plastic hinge model from component test results.

${ }^{2}$ Plastic hinge model from the recommended values in Table 3.

Fig. 5. Component test specimen: (a) at the time severe strength degradation began (0.09 radian); (b) plastic deformation and fracture at 0.0911 radian

Fig. 6. STMF subassemblage overall dimensions (unit: $\mathrm{mm}$ )

Fig. 7. Special features of STMF subassemblage (unit: $\mathrm{mm}$ )

Fig. 8. Test Setup

Fig. 9. Displacement (drift ratio) history

Fig. 10. Special segment at different drift levels

Fig. 11. Hysteresis response of subassemblage

Notes: ${ }^{1}$ Results from pushover analysis using plastic hinge model from component test results.

${ }^{2}$ Results from pushover analysis using plastic hinge model from the recommended values in Table 3.

Fig. 12. Equivalent shear force $\left(V_{n e}\right)$ versus story drift ratio

Notes: ${ }^{1}$ Results from pushover analysis using plastic hinge model from component test results.

${ }^{2}$ Results from pushover analysis using plastic hinge model from the recommended values in Table 3.

Fig. 13. Failure of specimens: (a) STMF subassemblage at the end of chord members in the special segment, (b) component test specimen

Fig. 14. Lateral bracing instrumentation

Fig. 15. Lateral bracing threaded rod calibration test setup

Fig. 16. Lateral bracing threaded rod calibration test results

Fig. 17. Lateral bracing forces: (a) maximum lateral bracing forces at different story drift levels, (b) lateral bracing forces at each corner of the special segment

Fig. 18. Cut locations for tensile test coupon specimens (unit: $\mathrm{mm}$ )

Fig. 19. Tensile coupon test results

Fig. 20. Maximum strain levels in exterior panels

Fig. 21. Hysteretic strain response of maximum strain level observed outside of the special segment

Fig. 22. Maximum strain levels in special segment panel

Fig. 23. Strain profile on top of the flange and along the length of chord member at the end of the special segment

Fig. 24. Generalized moment-rotation relation for plastic hinges

Fig. 25. XTRACT analysis and results: (a) material models based on material test results of flange and web of component test specimen, (b) moment curvature of component test specimen 


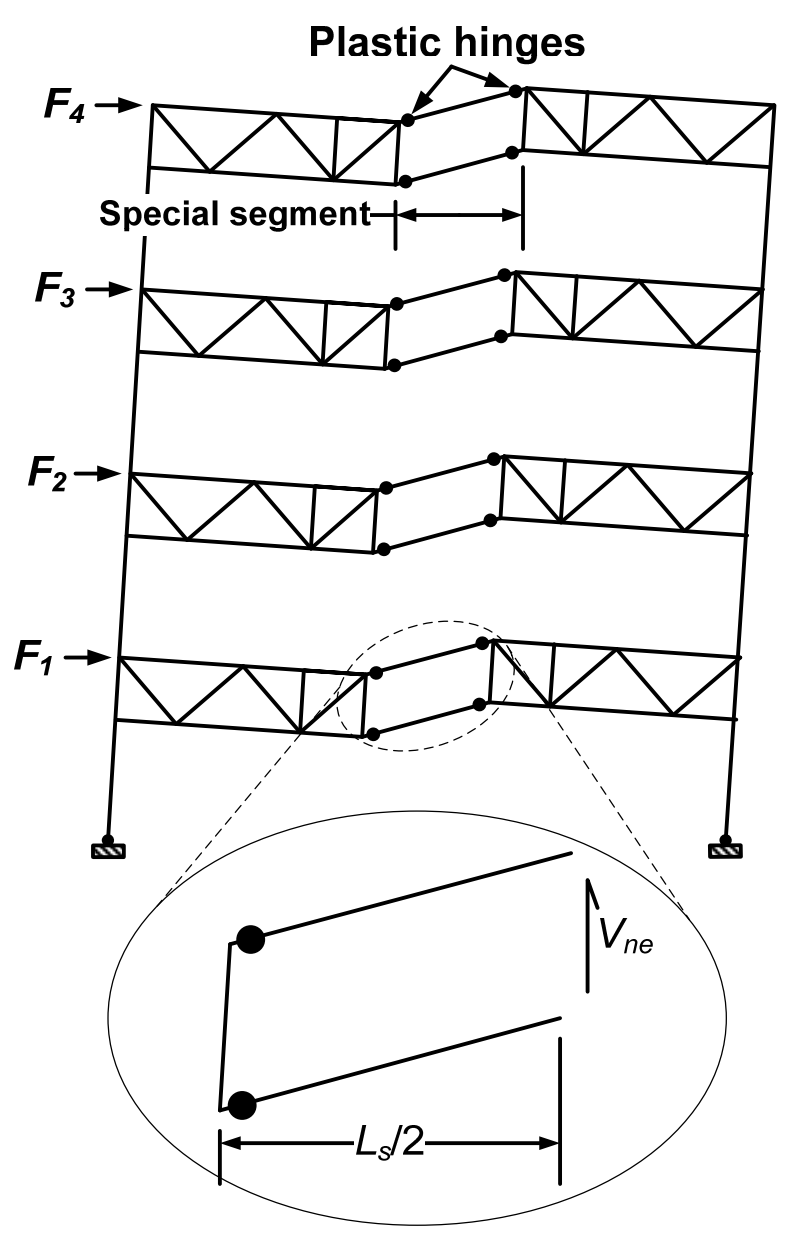

(a)

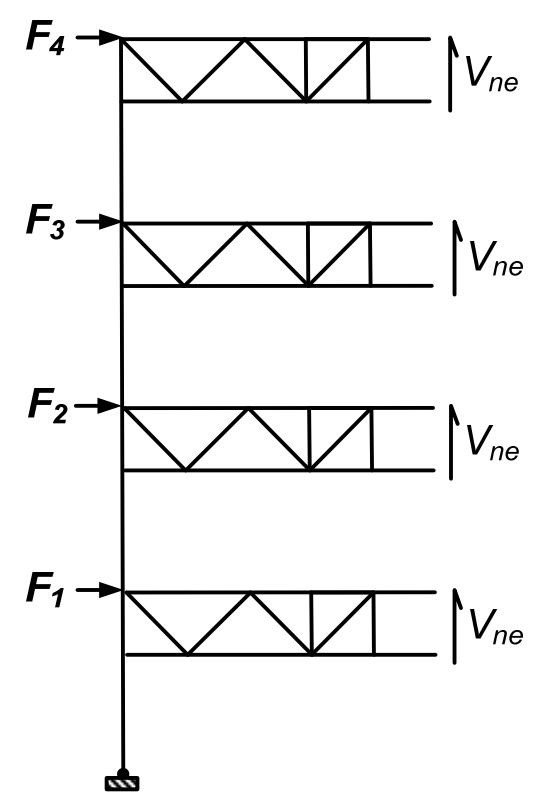

Note: Gravity loading is not shown here

(b)

Fig. 1. STMF: (a) Yielding mechanism adapted from Goel and Chao (2008), (b) free-body diagram of column tree and associated truss girder portions adapted from Goel and Chao (2008) 


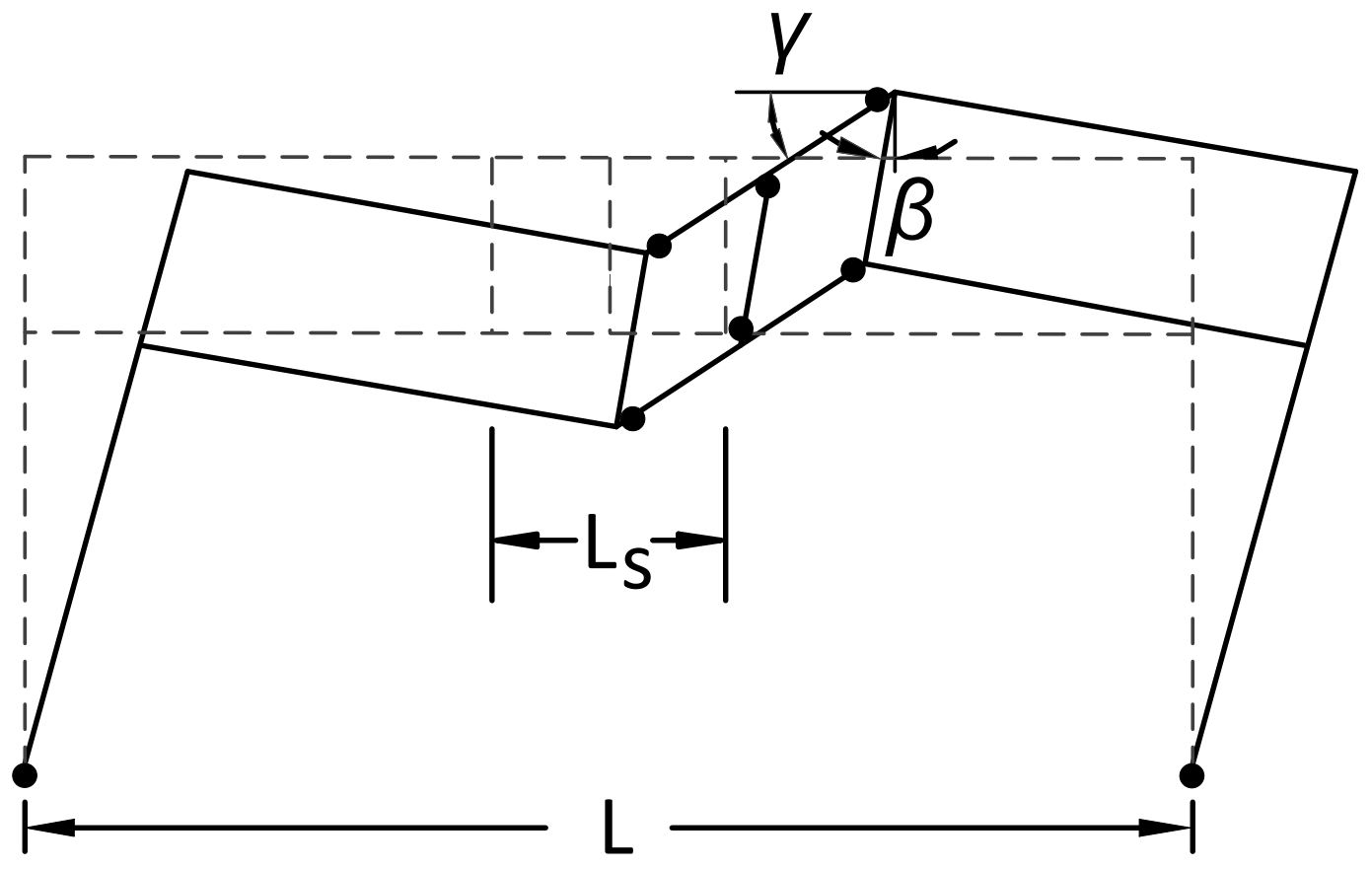

Fig. 2. Deformed shape of STMF

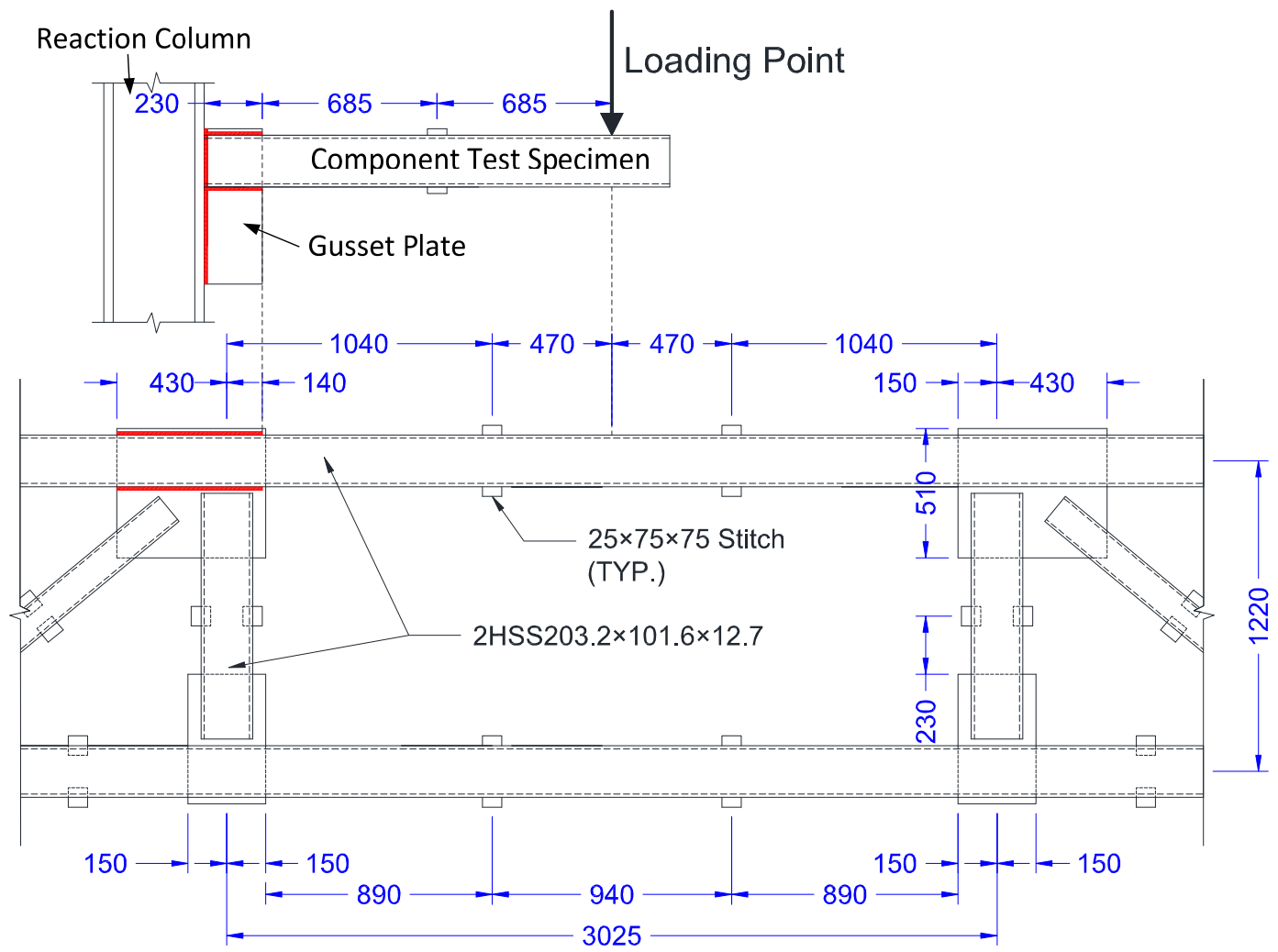

Fig. 3. Component test specimen representing chord members in the special segment (unit: $\mathrm{mm}$ ) 


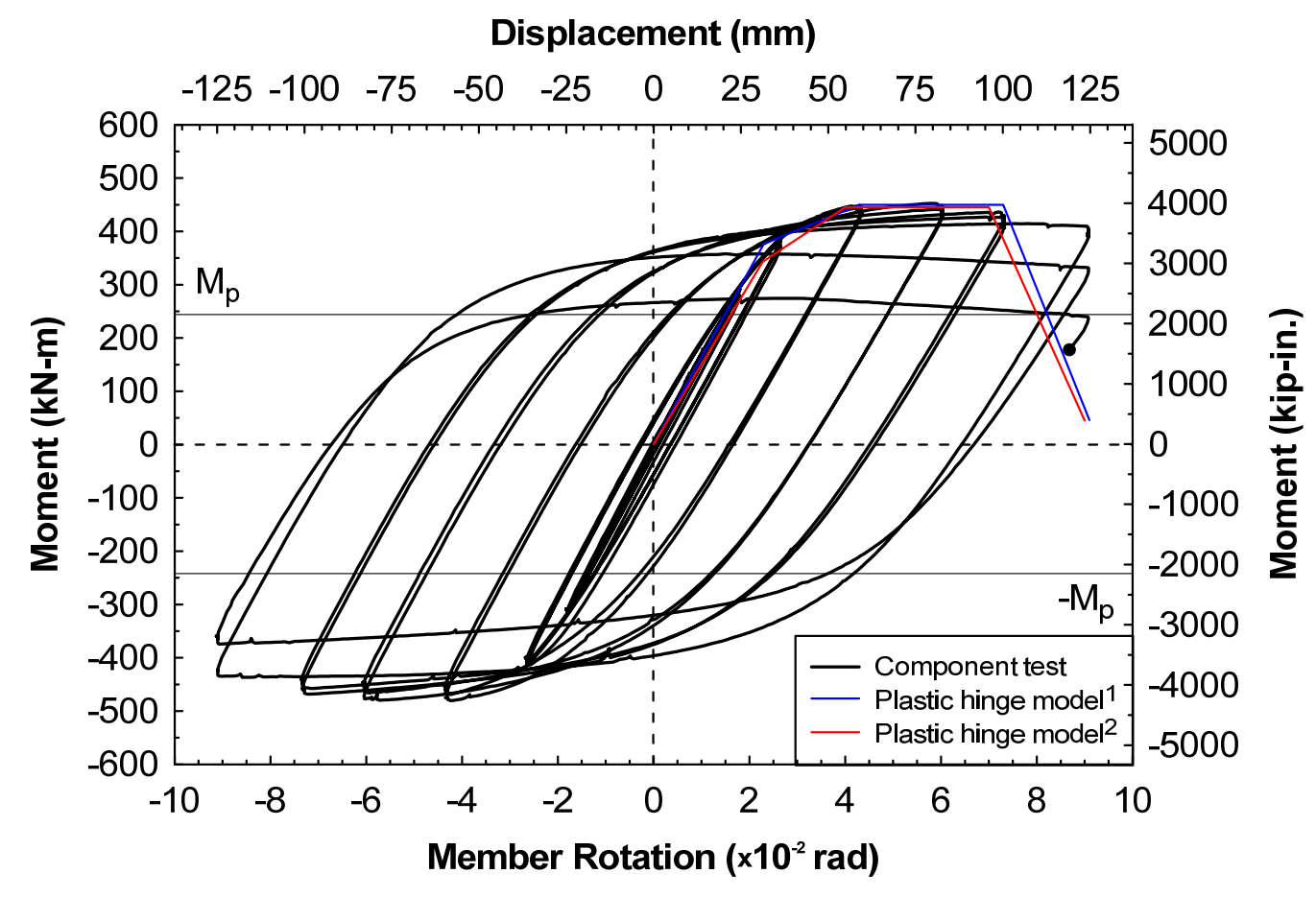

Fig. 4. Hysteresis response of component specimen and nonlinear models of plastic hinge

Notes: ${ }^{1}$ Plastic hinge model from component test results.

${ }^{2}$ Plastic hinge model from the recommended values in Table 3.

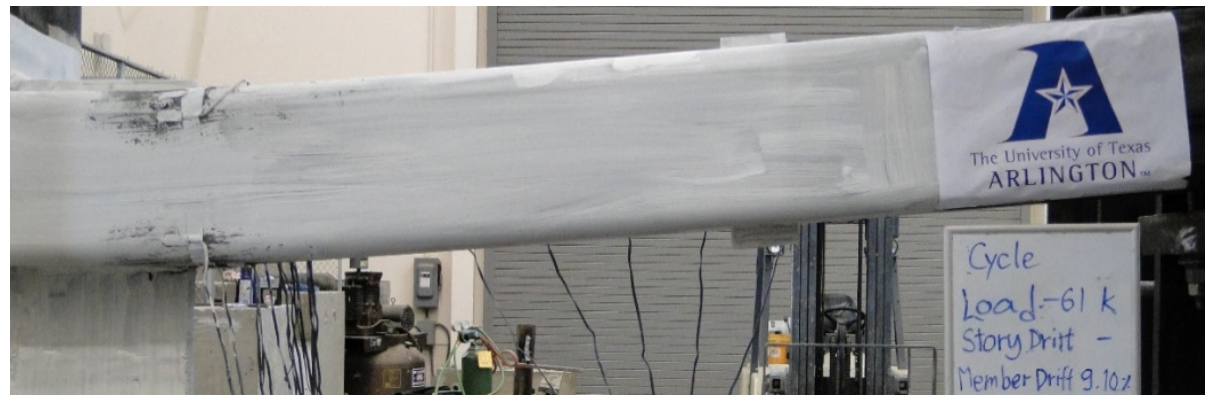

(a)

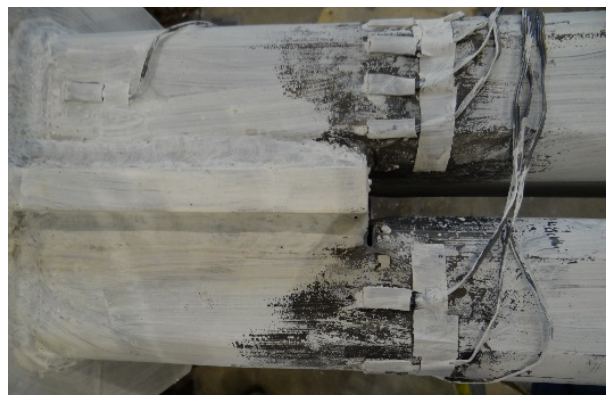

(b)

Fig. 5. Component test specimen: (a) at the time severe strength degradation began (0.09 radian); (b) plastic deformation and fracture at 0.0911 radian 


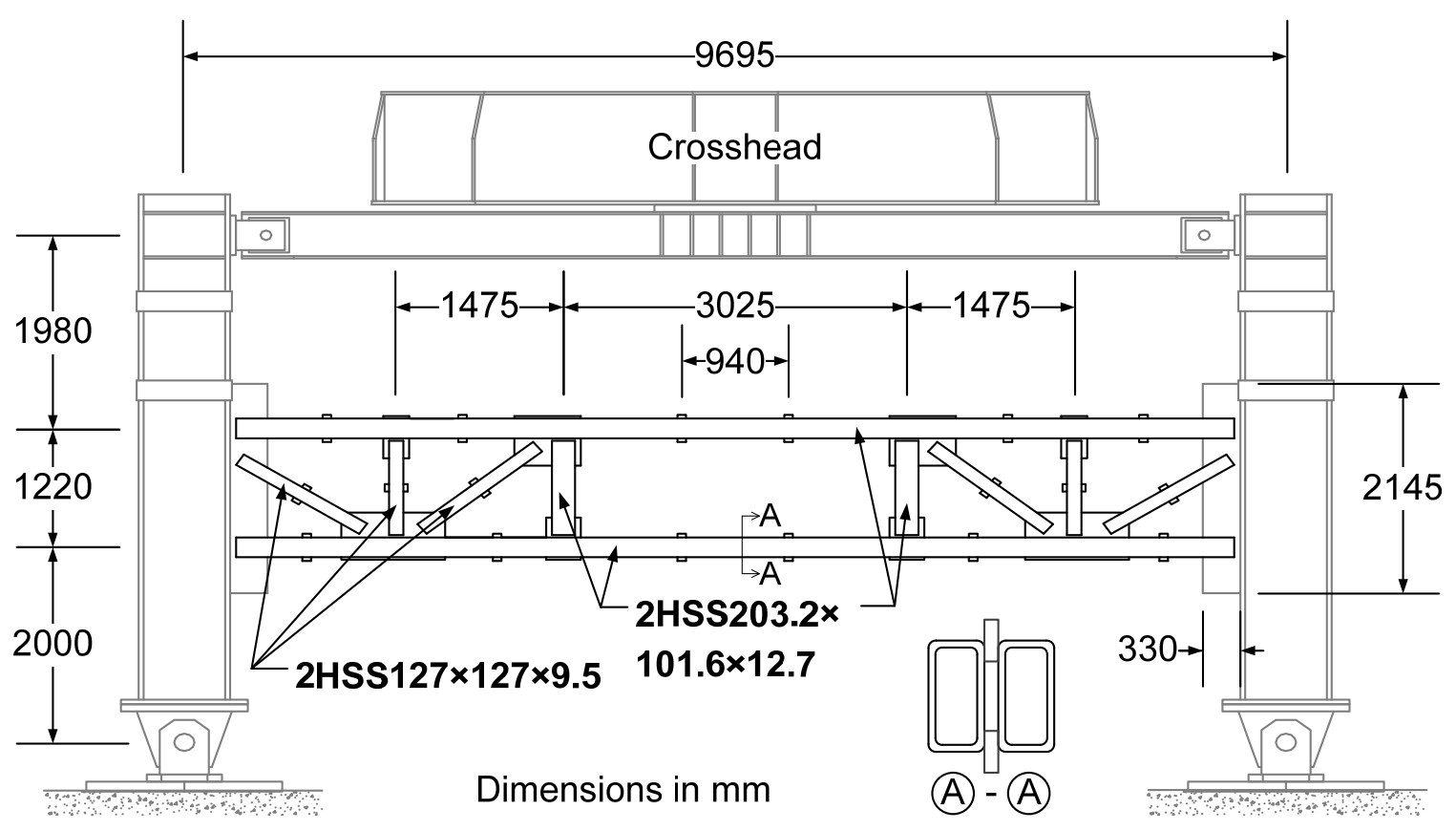

Fig. 6. STMF subassemblage overall dimensions (unit: $\mathrm{mm}$ )

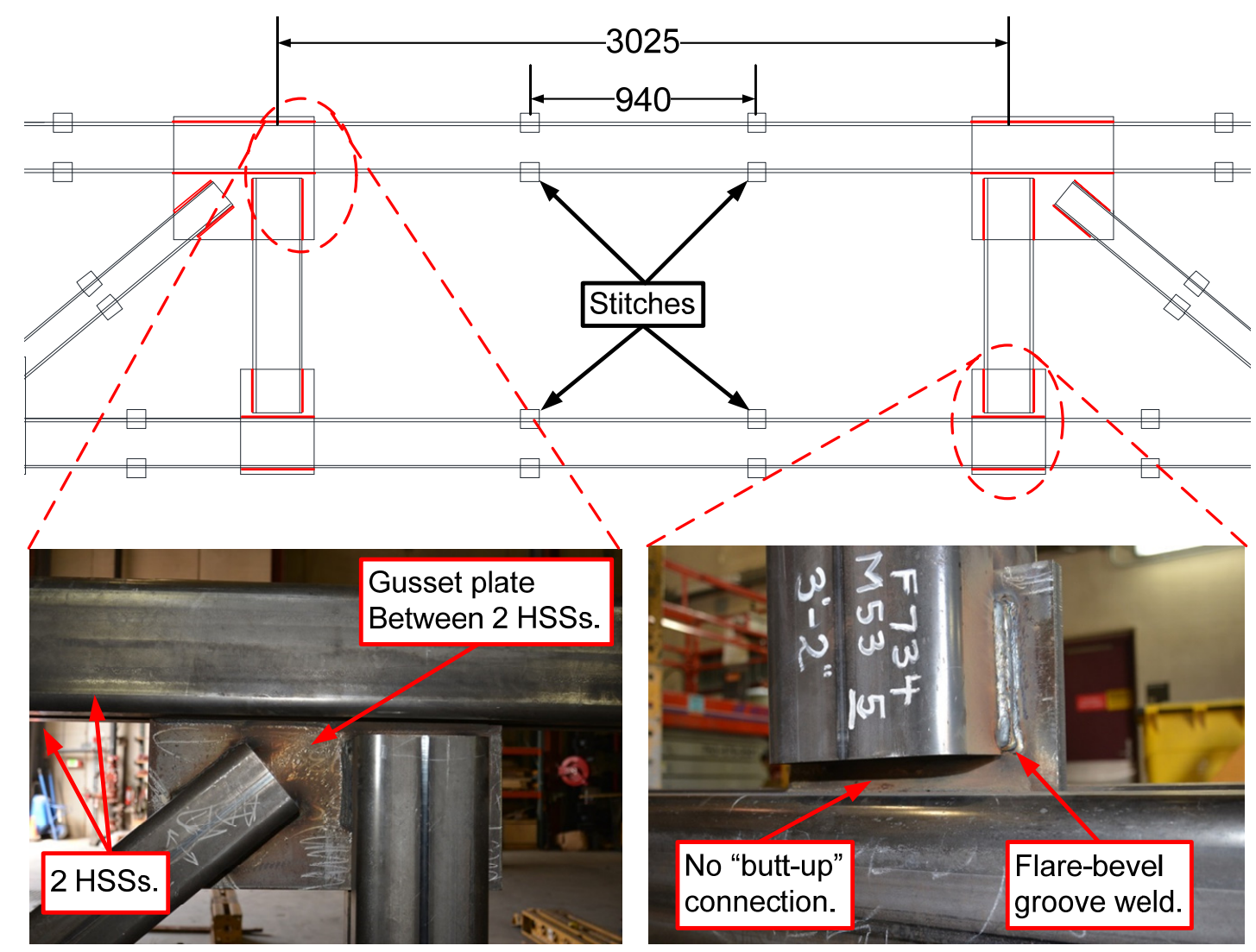

Fig. 7. Special features of STMF subassemblage (unit: $\mathrm{mm}$ ) 


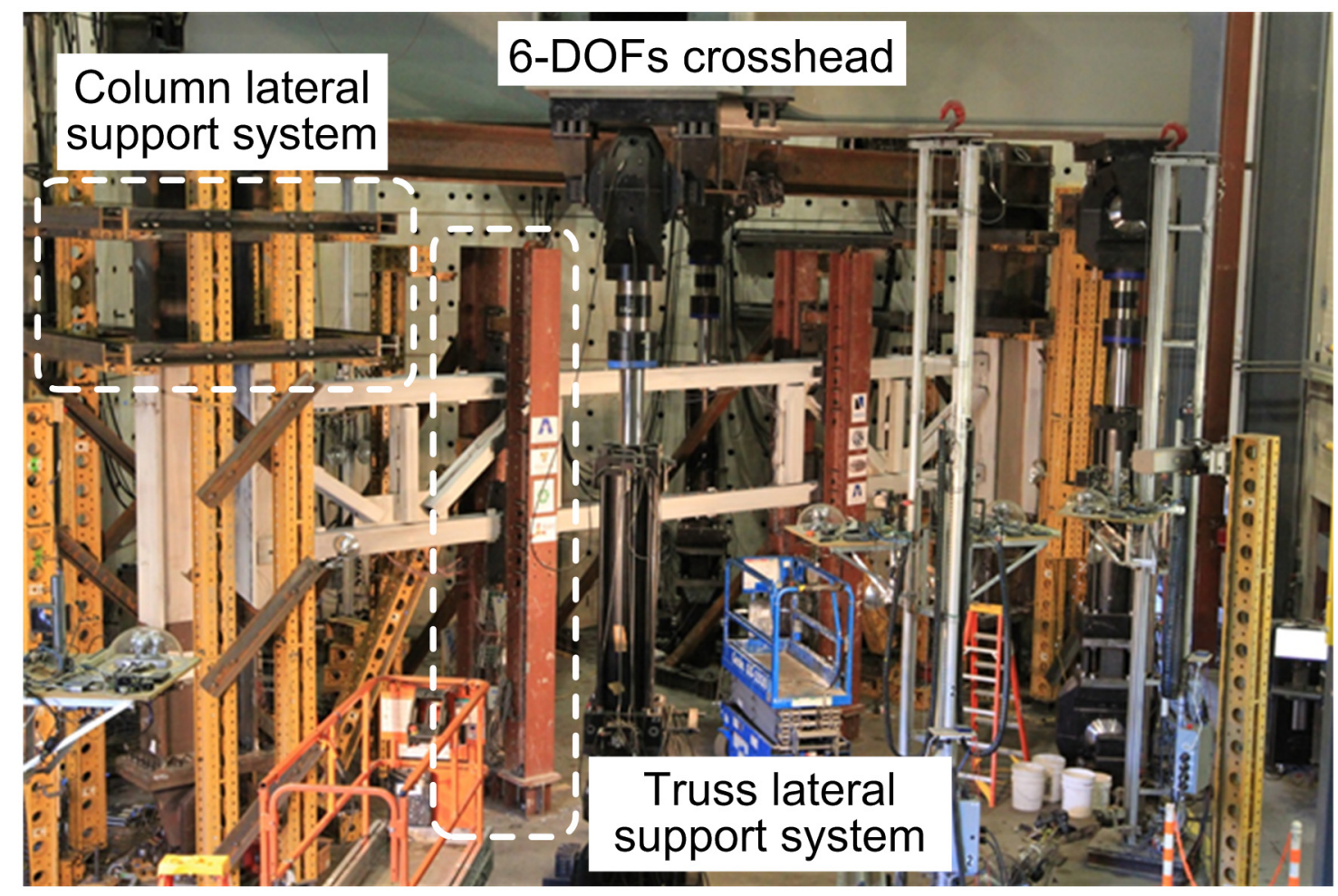

Fig. 8. Test Setup

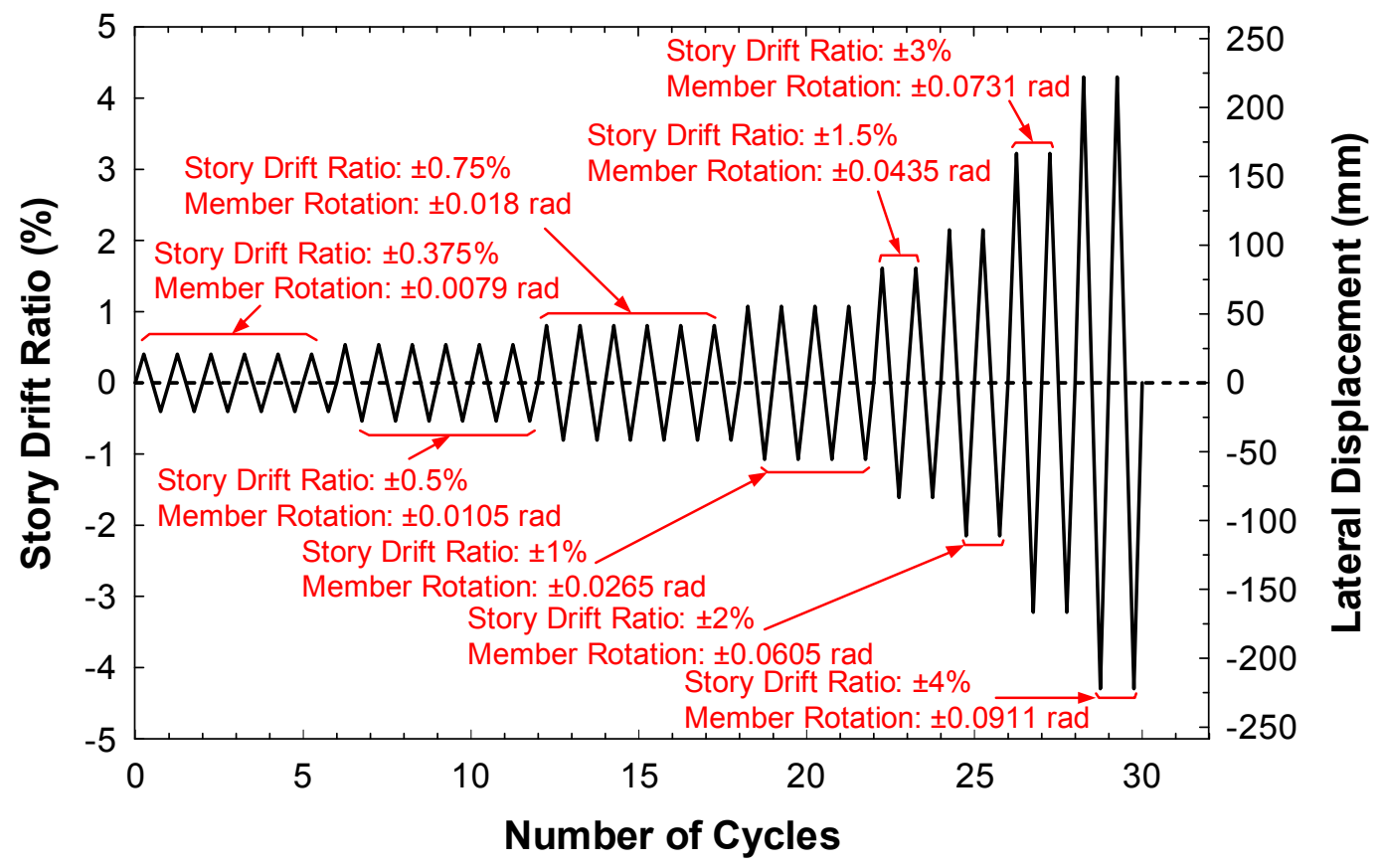

Fig. 9. Displacement (drift ratio) history 


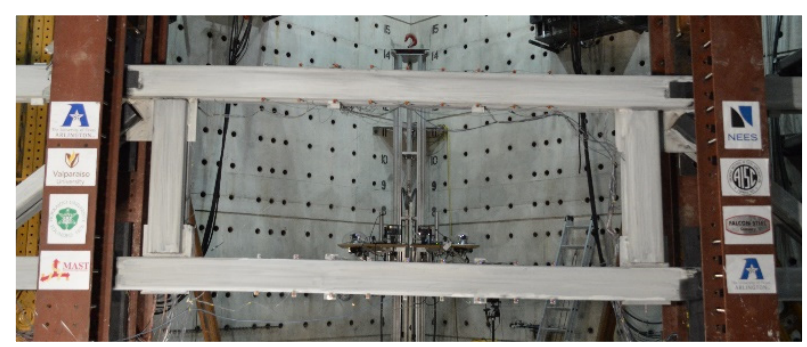

$+1 \%$ Drift

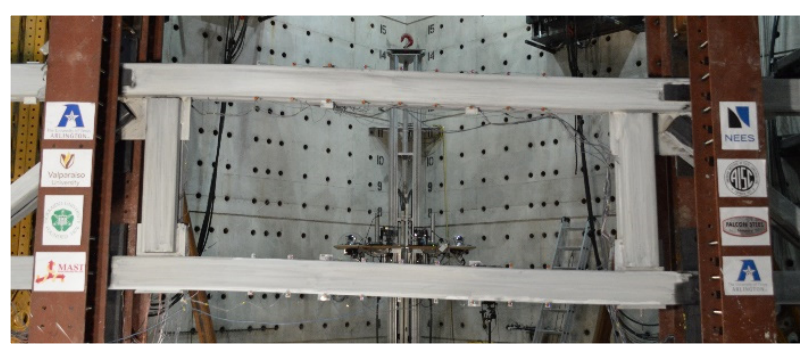

$+1.5 \%$ Drift

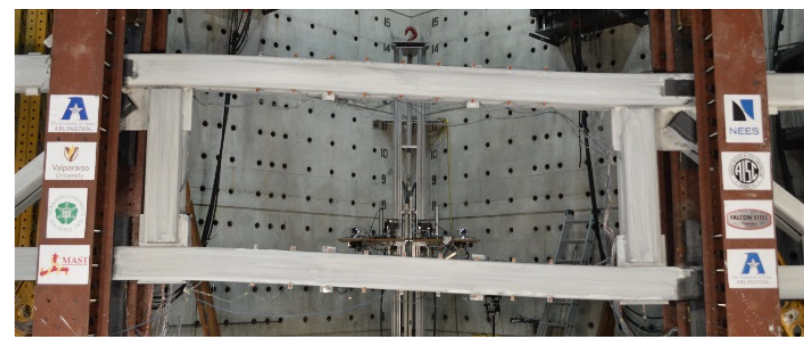

$+2 \%$ Drift

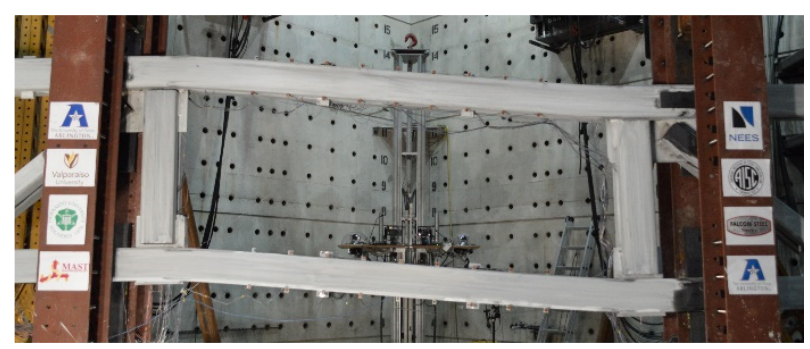

$+3 \%$ Drift

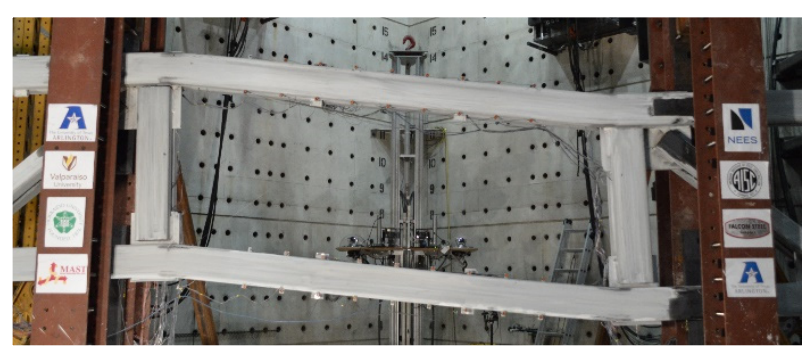

$+4 \%$ Drift

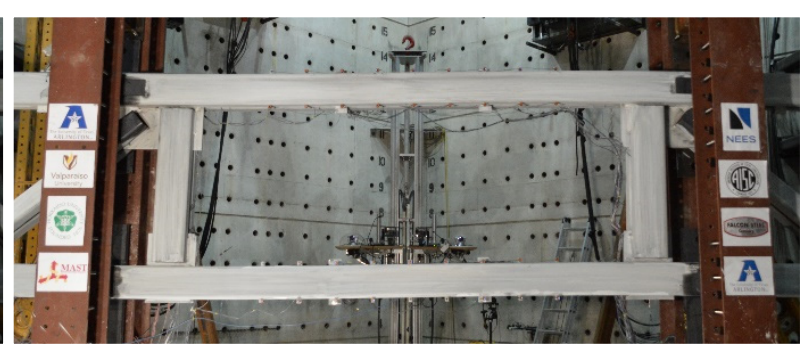

$-1 \%$ Drift

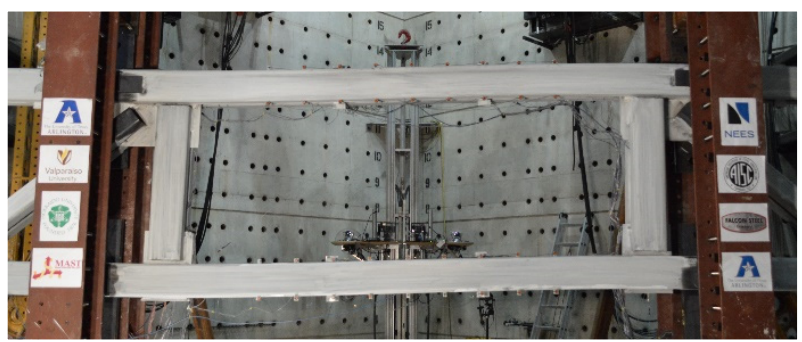

$-1.5 \%$ Drift

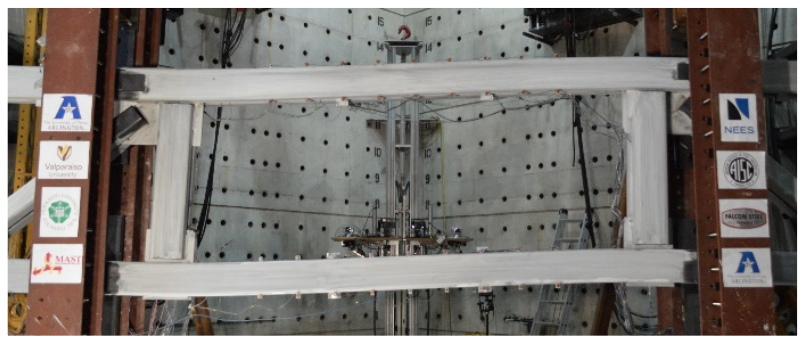

$-2 \%$ Drift

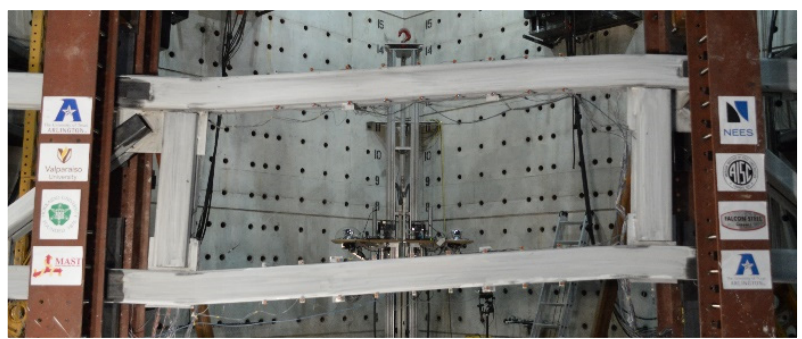

$-3 \%$ Drift

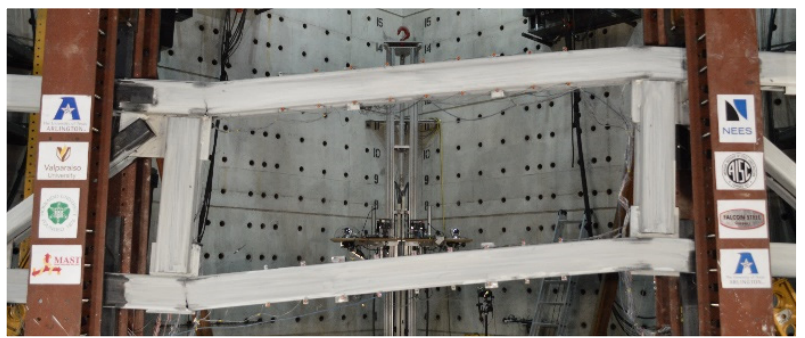

$-4 \%$ Drift

Fig. 10. Special segment at different drift levels 


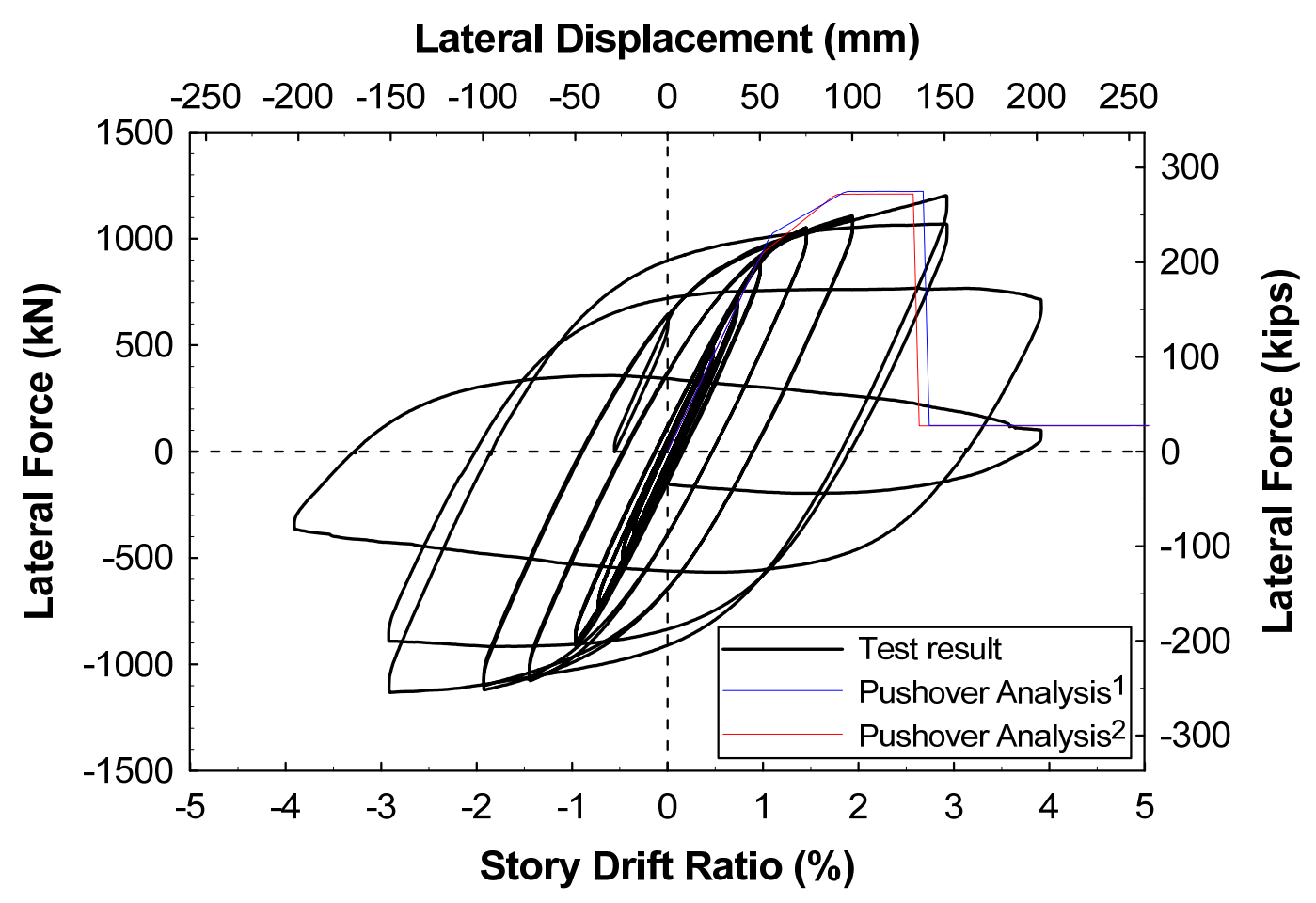

Fig. 11. Hysteresis response of subassemblage

Notes: ${ }^{1}$ Results from pushover analysis using plastic hinge model from component test results.

${ }^{2}$ Results from pushover analysis using plastic hinge model from the recommended values in Table 3. 


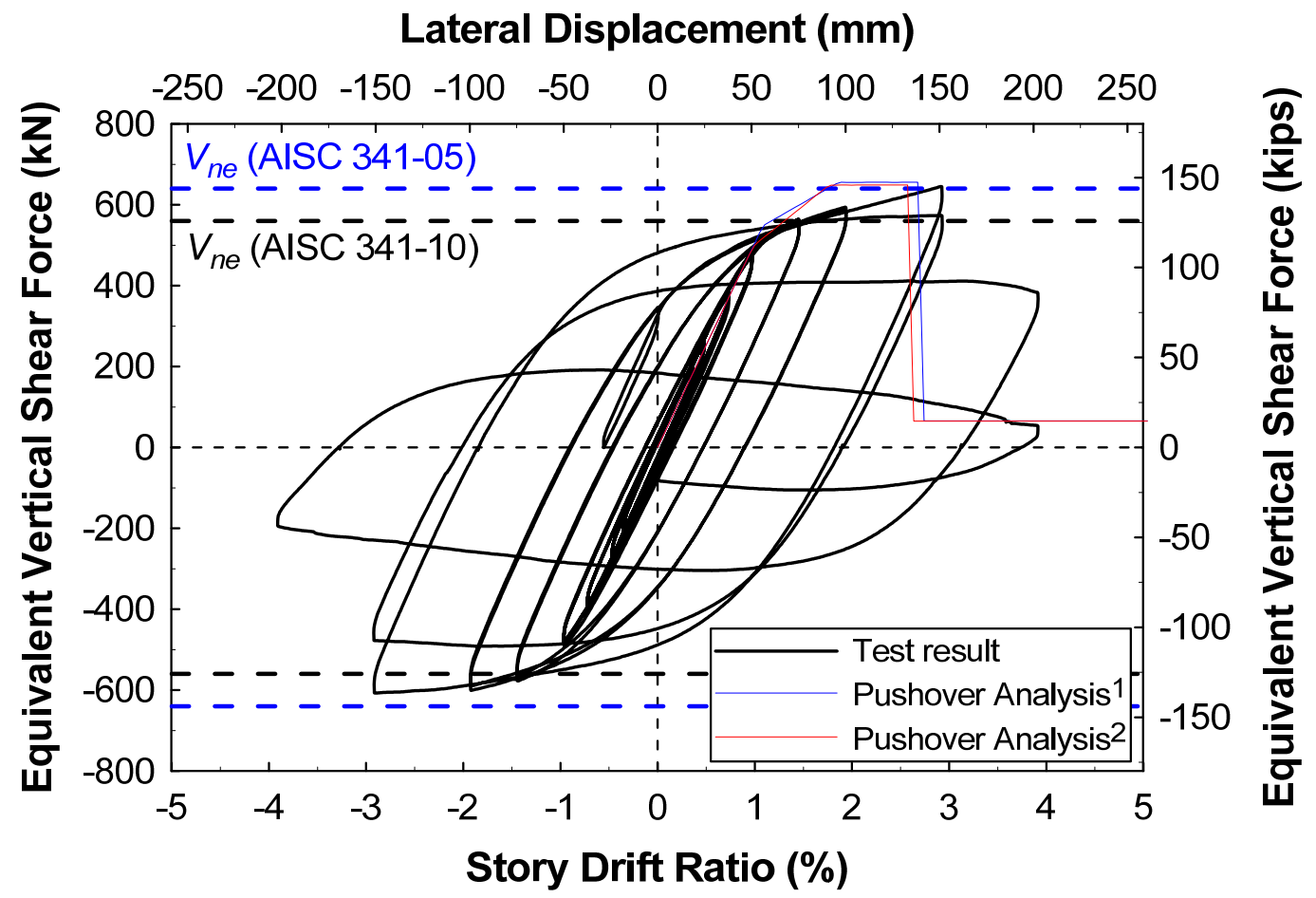

Fig. 12. Equivalent shear force $\left(V_{n e}\right)$ versus story drift ratio

Notes: ${ }^{1}$ Results from pushover analysis using plastic hinge model from component test results.

${ }^{2}$ Results from pushover analysis using plastic hinge model from the recommended values in Table 3.

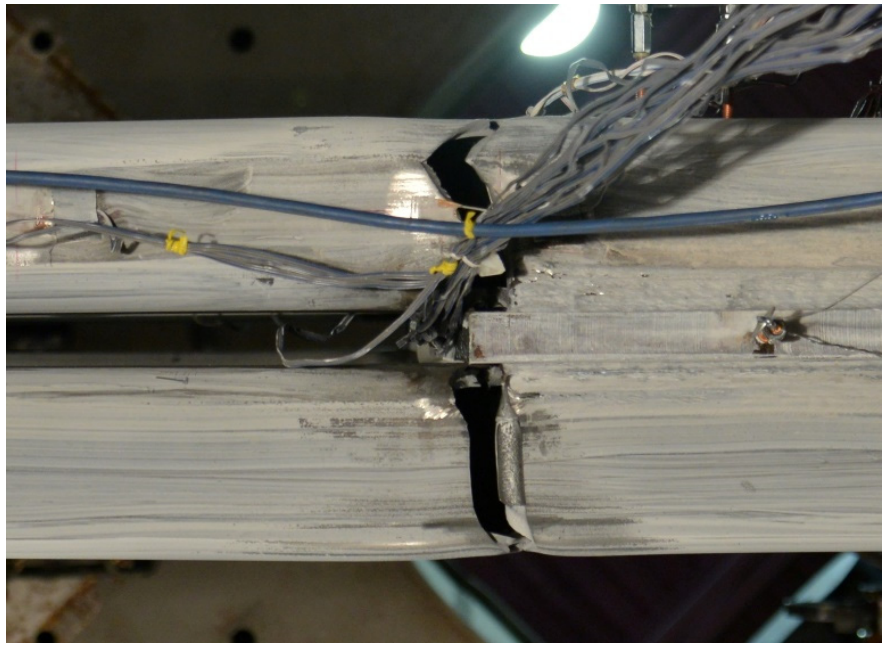

(a)

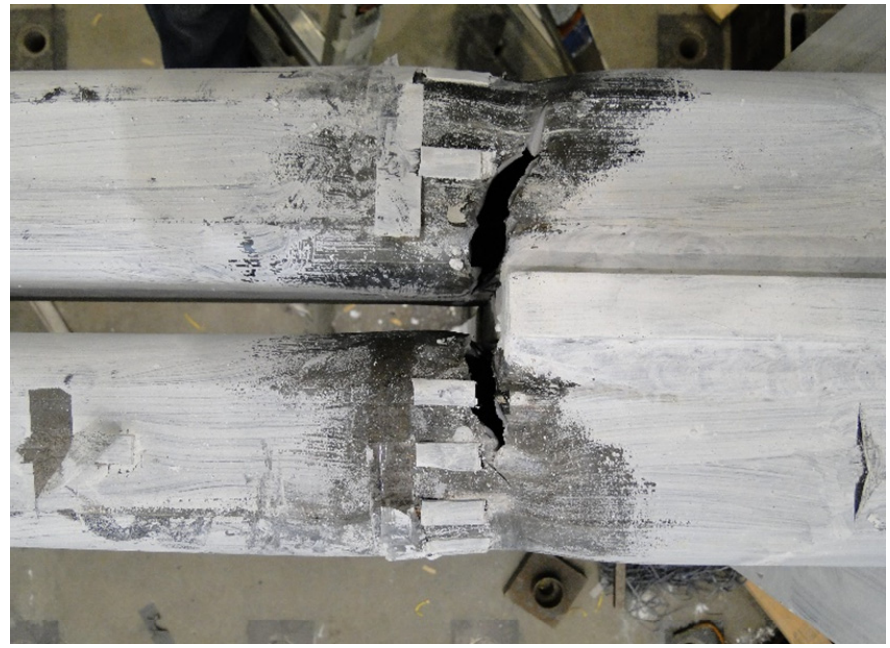

(b)

Fig. 13. Failure of specimens: (a) STMF subassemblage at the end of chord members in the special segment, (b) component test specimen 


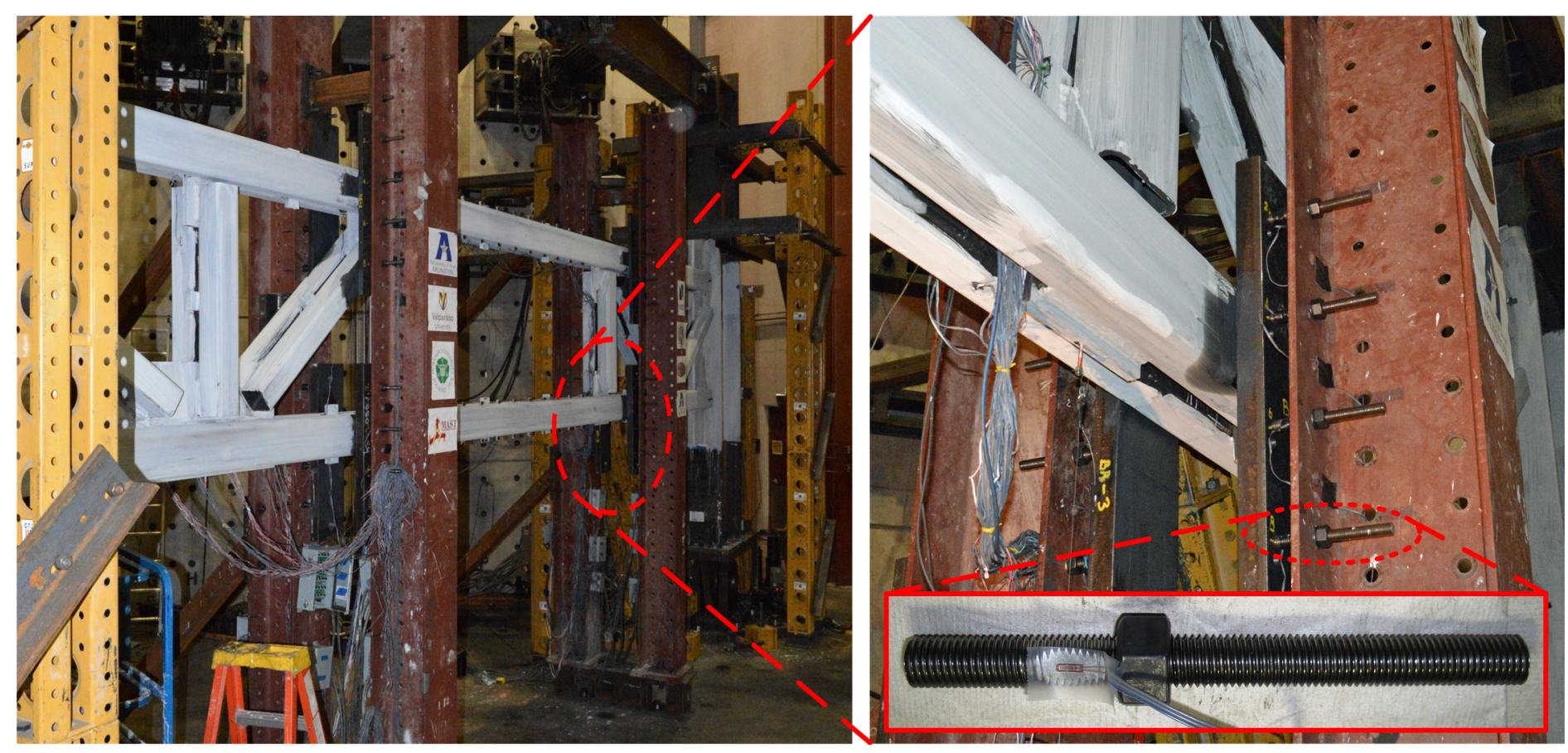

Fig. 14. Lateral bracing instrumentation

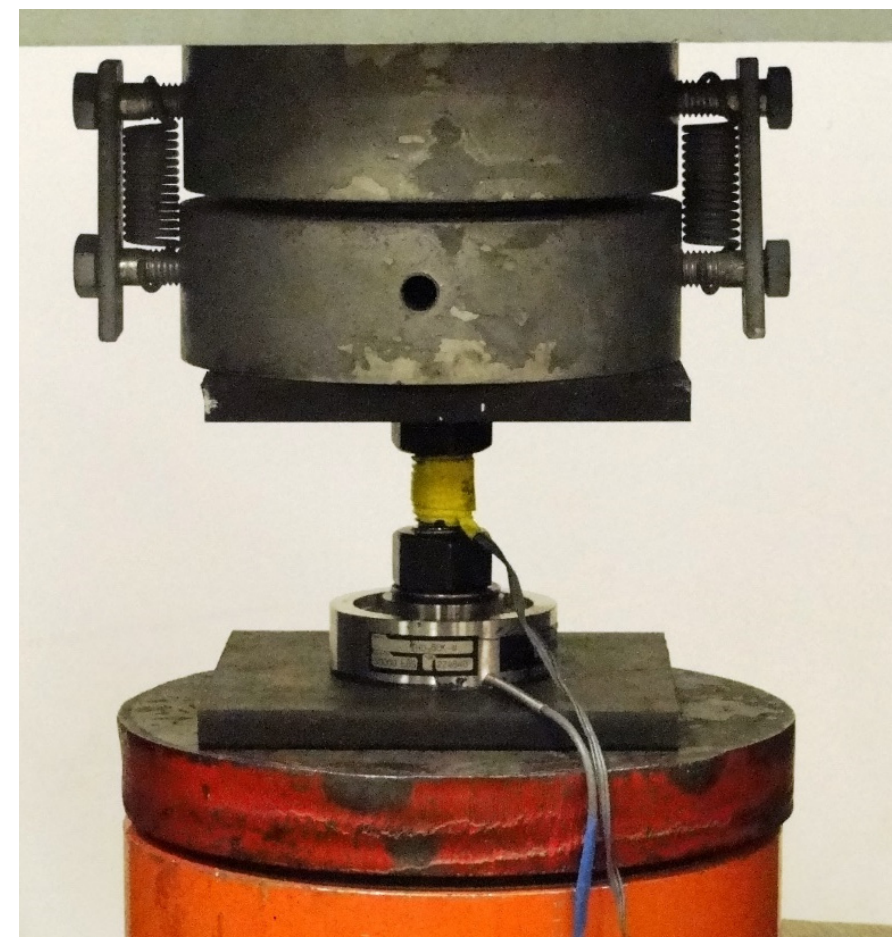

Fig. 15. Lateral bracing threaded rod calibration test setup 


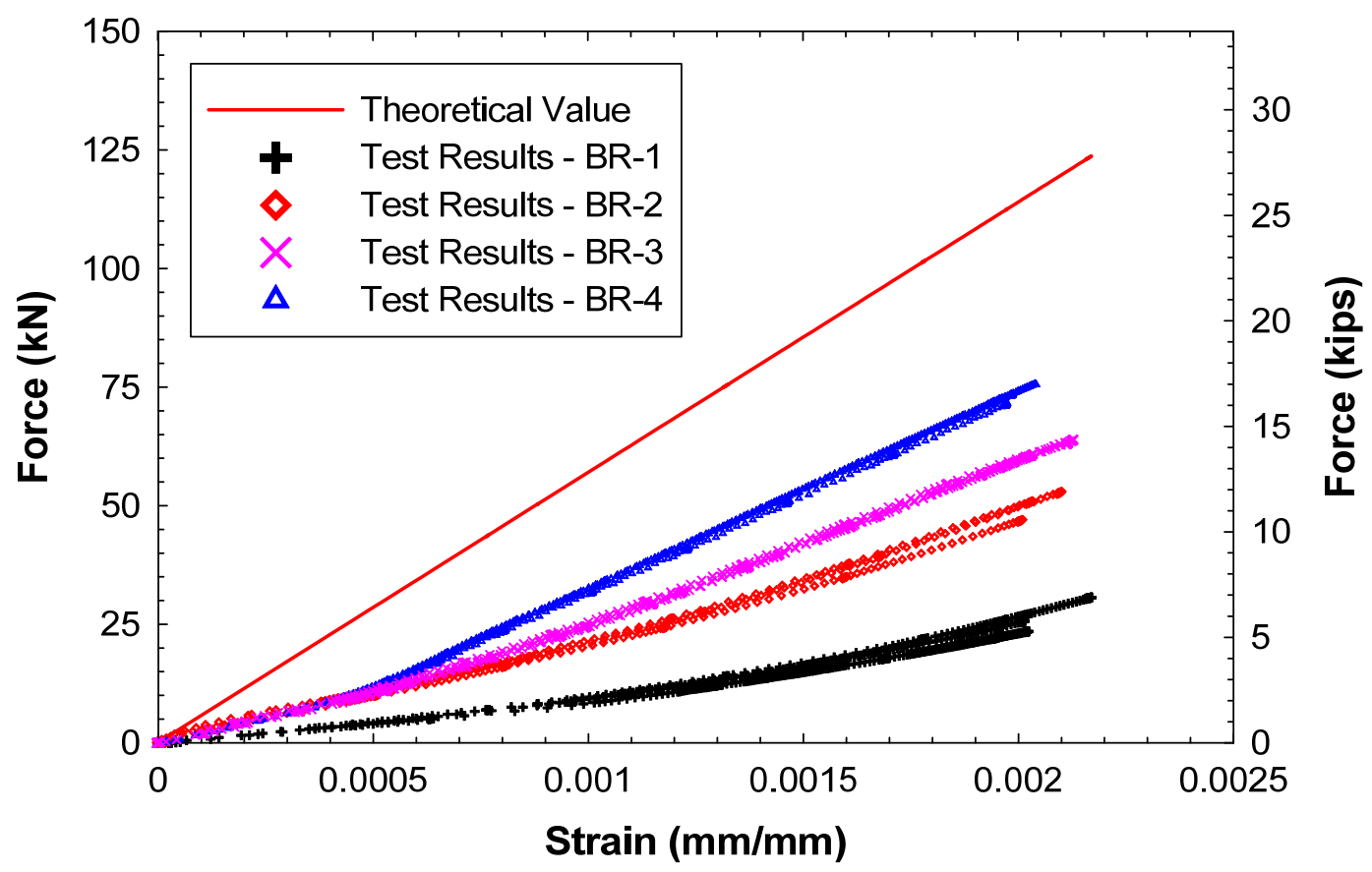

Fig. 16. Lateral bracing threaded rod calibration test results 


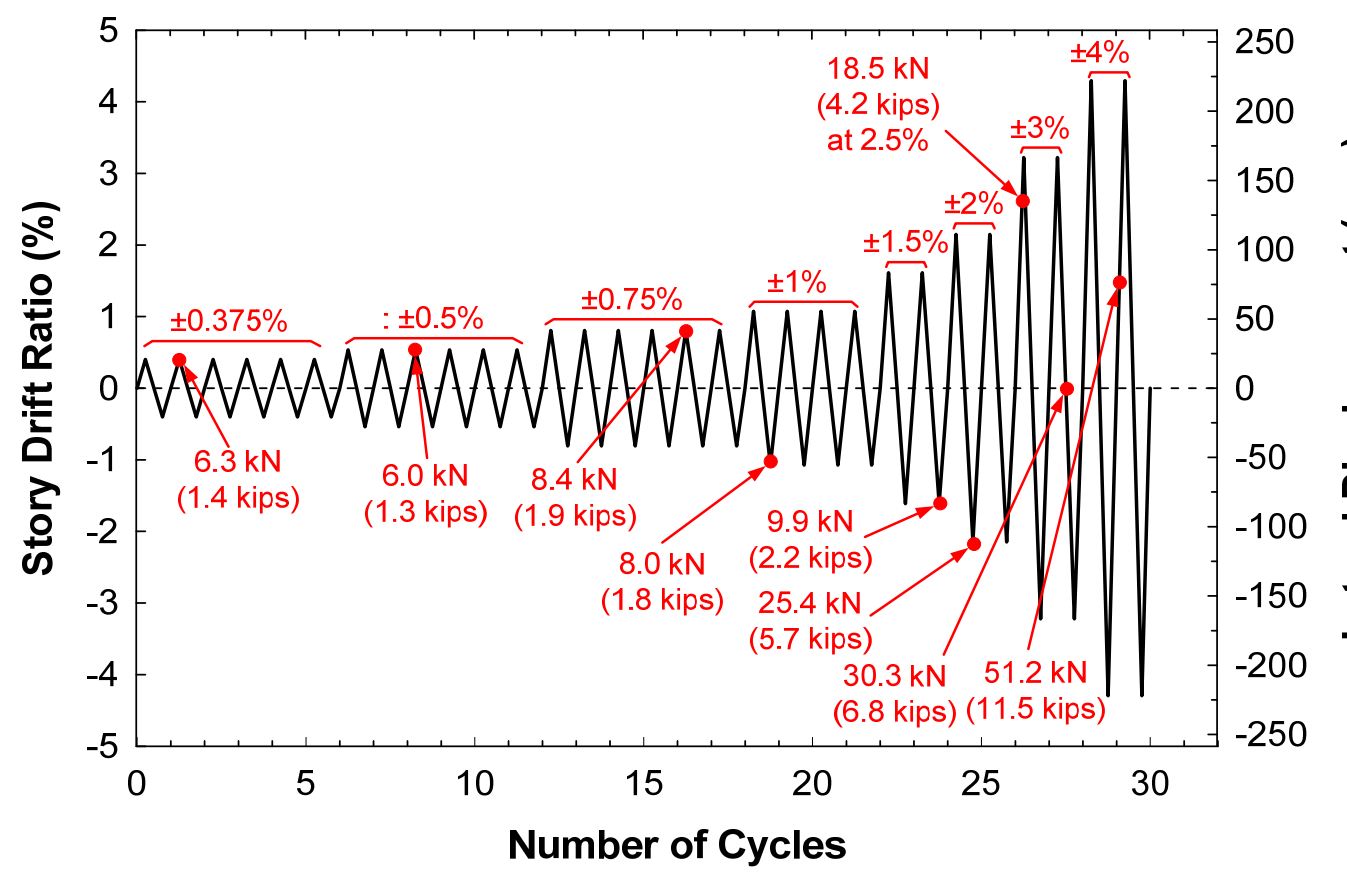

I

(a)

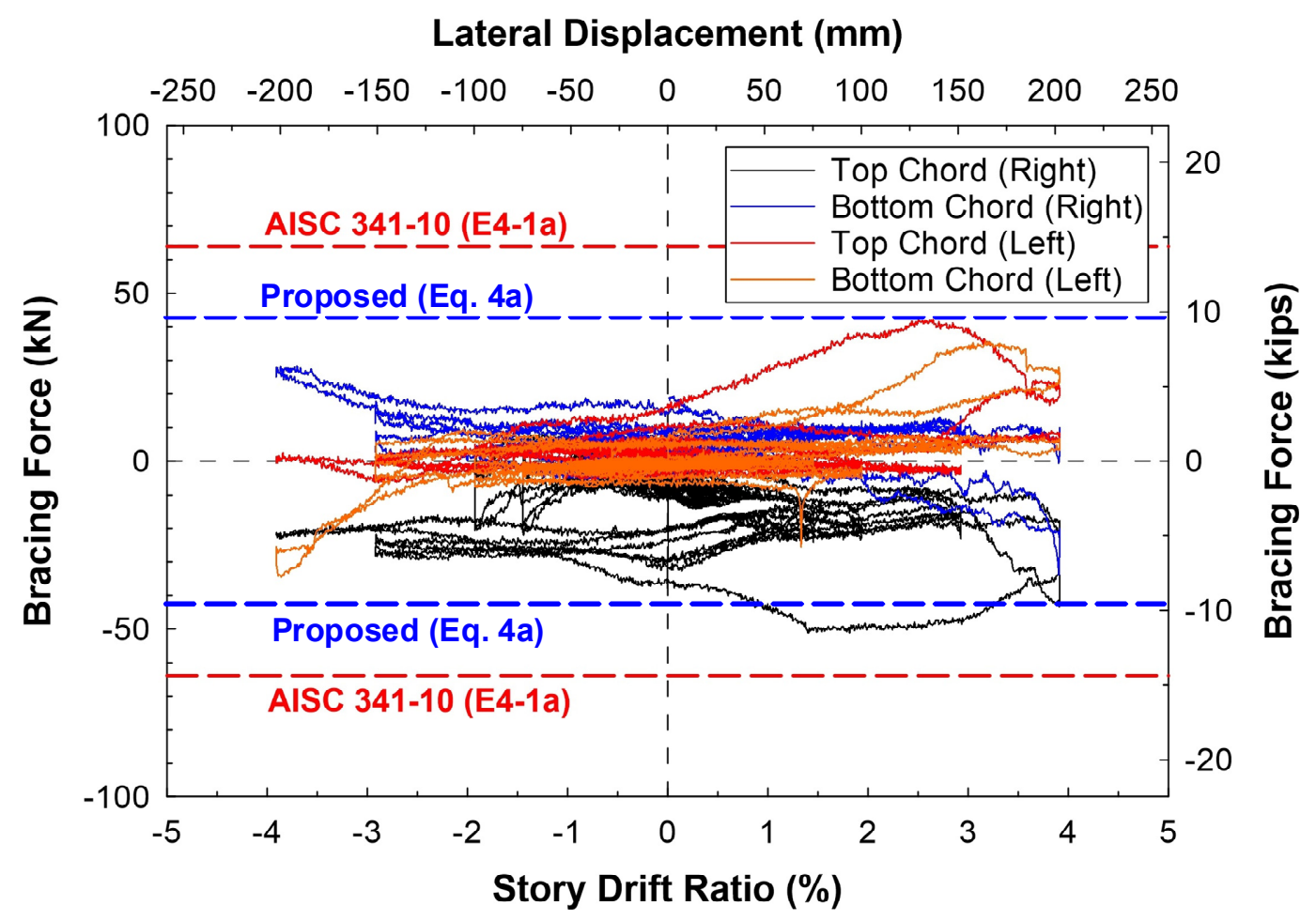

(b)

Fig. 17. Lateral bracing forces: (a) maximum lateral bracing forces at different story drift levels, (b) lateral bracing forces at each corner of the special segment 


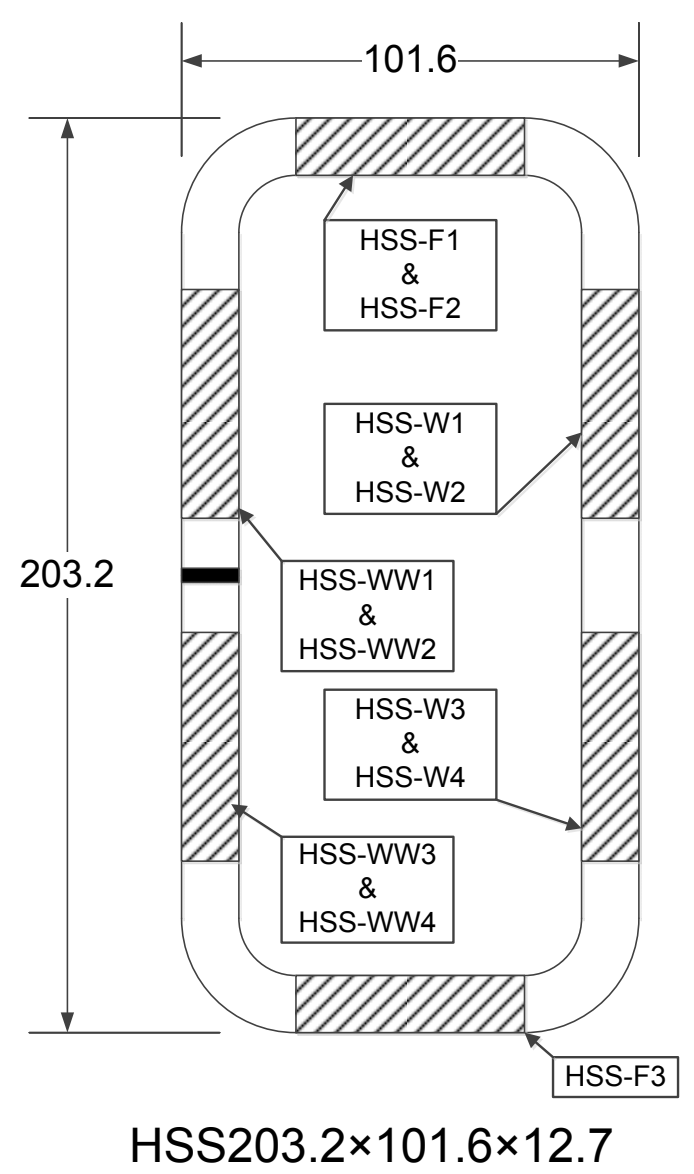

Fig. 18. Cut locations for tensile test coupon specimens (unit: $\mathrm{mm}$ ) 

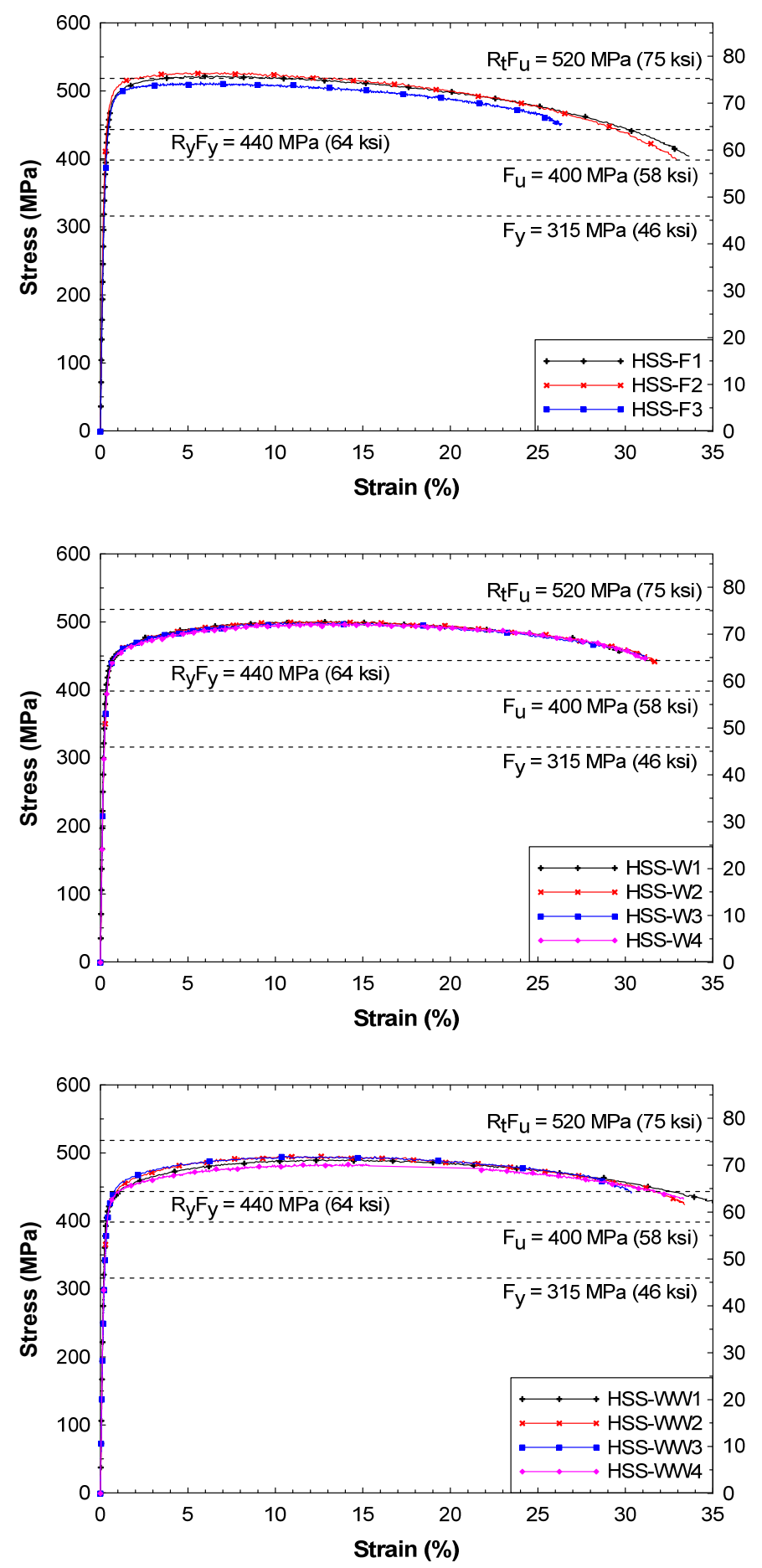
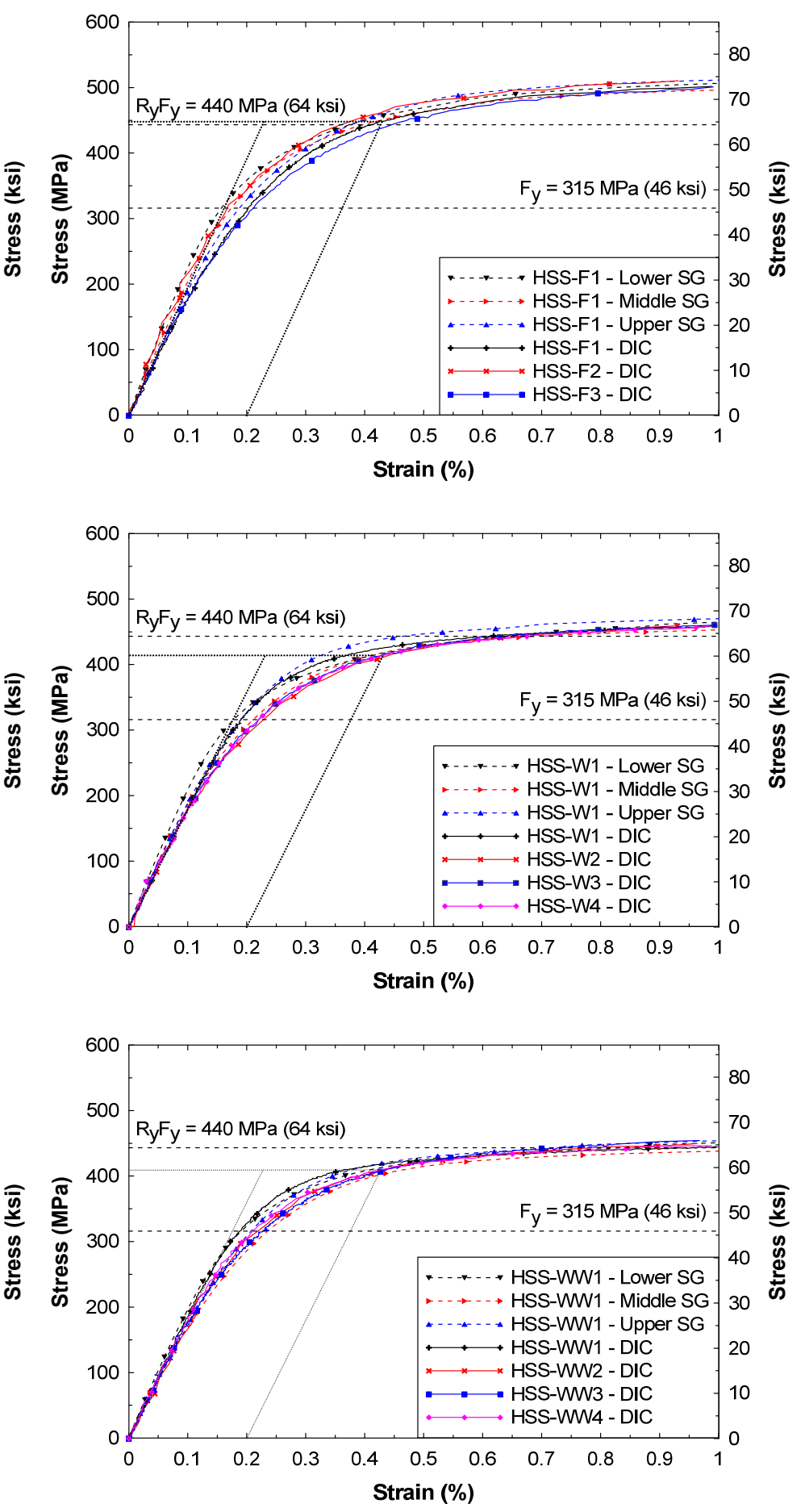

Fig. 19. Tensile coupon test results 


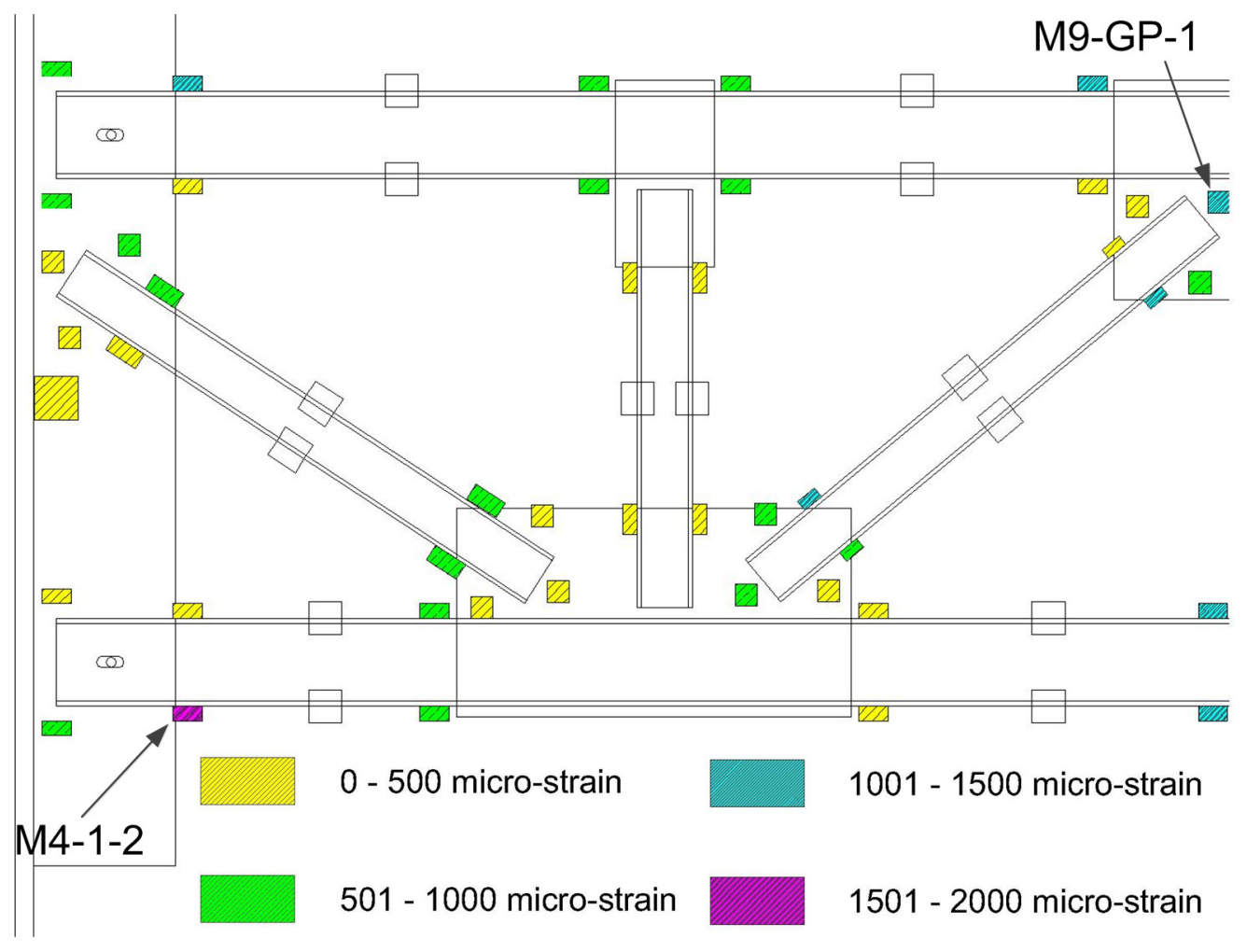

Fig. 20. Maximum strain levels in exterior panels

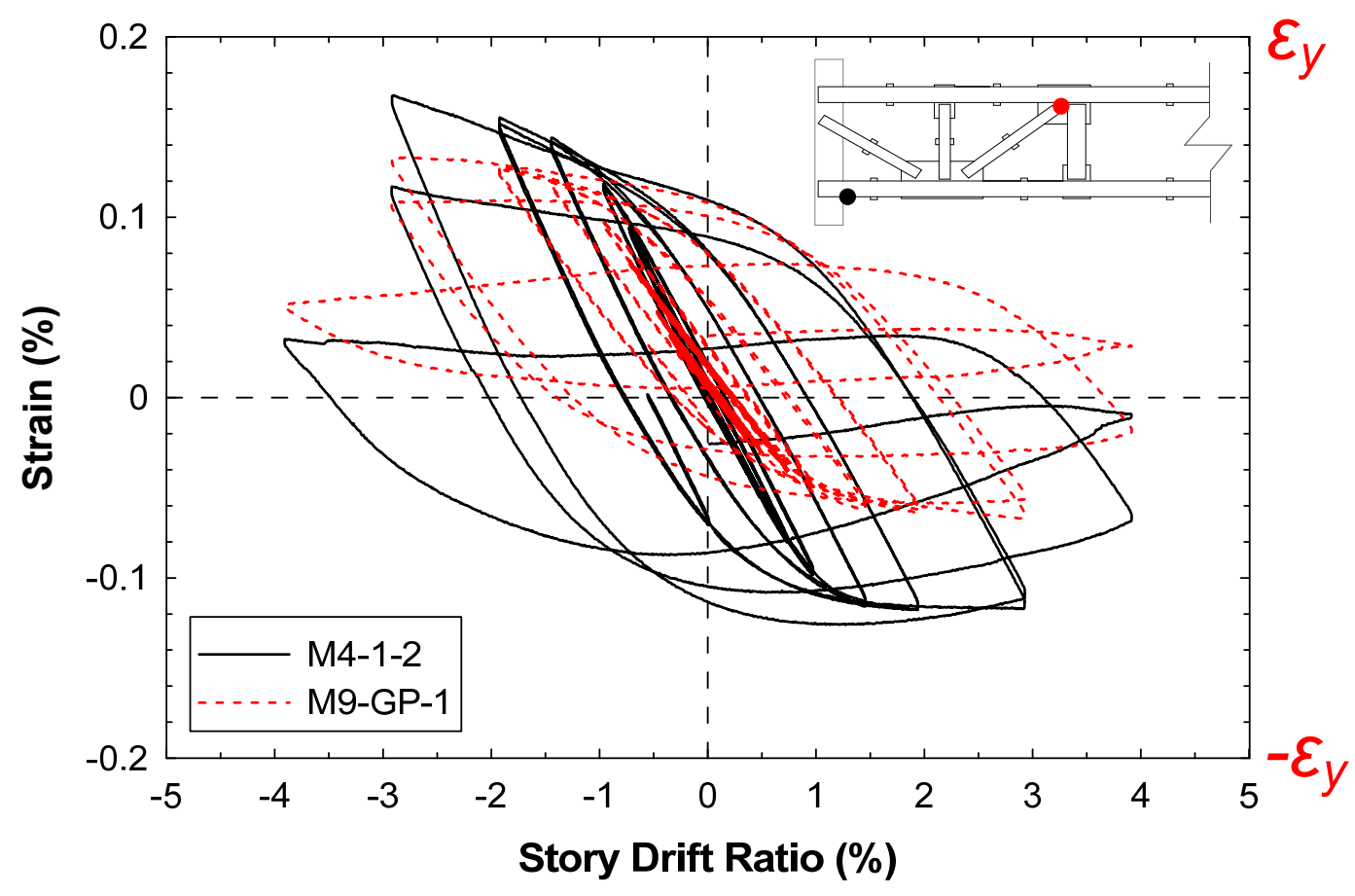

Fig. 21. Hysteretic strain response of maximum strain level observed outside of the special segment 


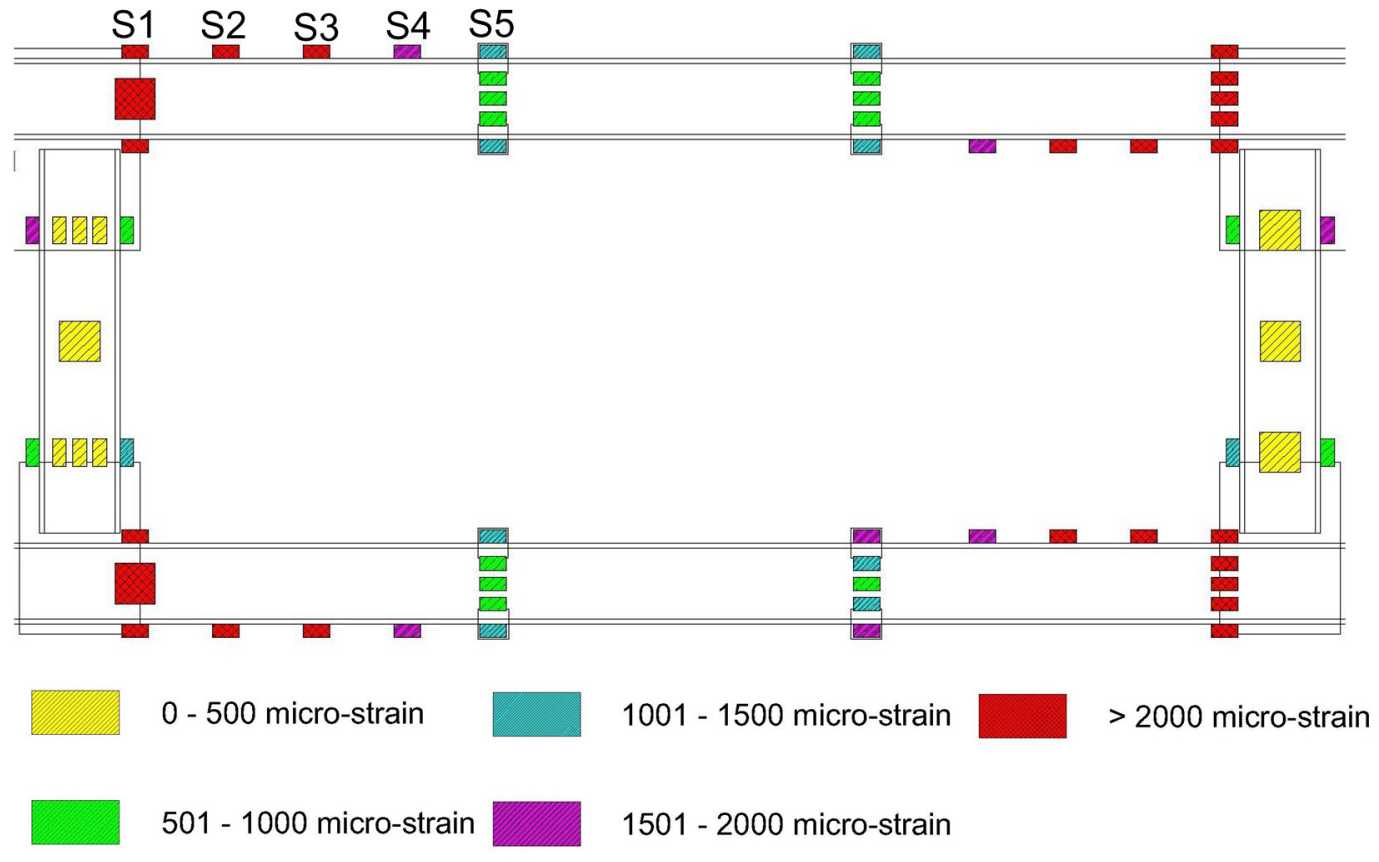

Fig. 22. Maximum strain levels in special segment panel 


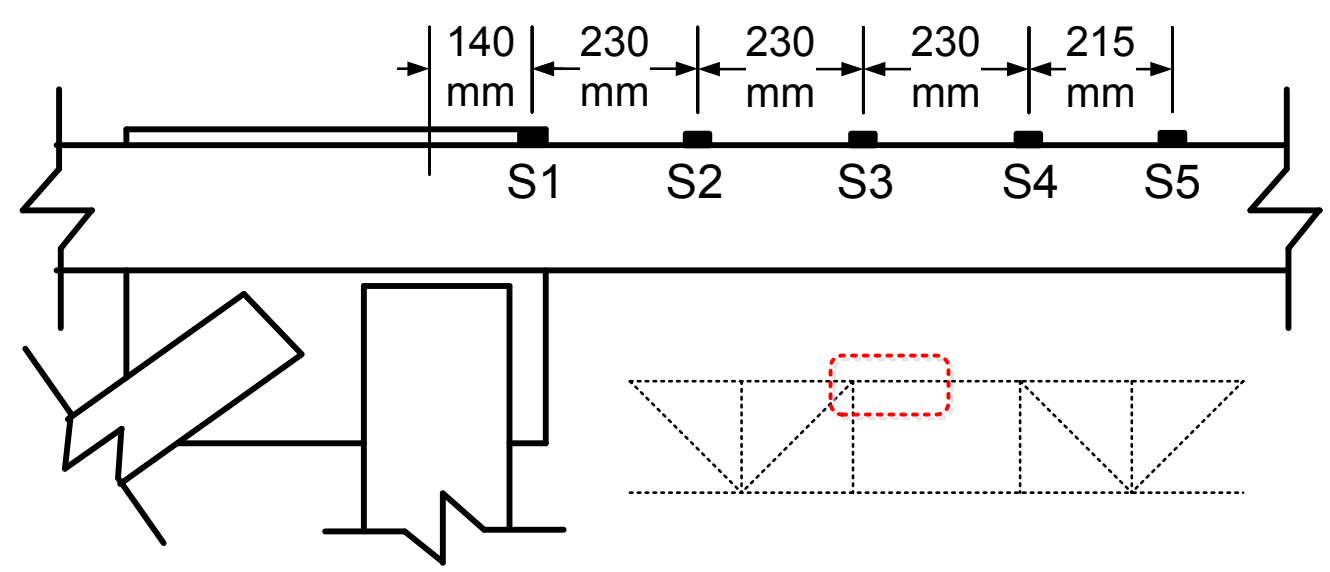

Distance from end of special segment (in.)

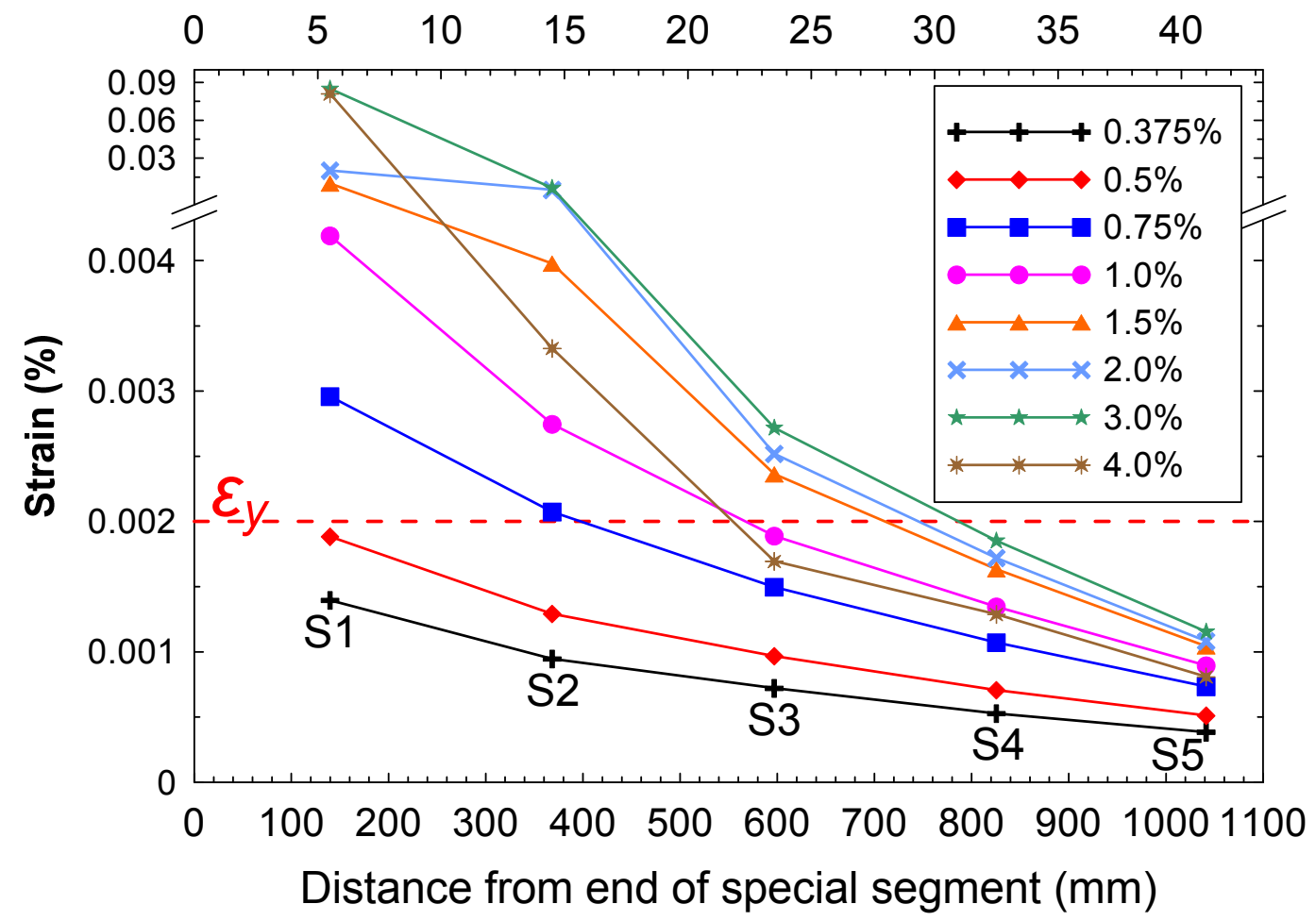

Fig. 23. Strain profile on top of the flange and along the length of chord member at the end of the special segment 


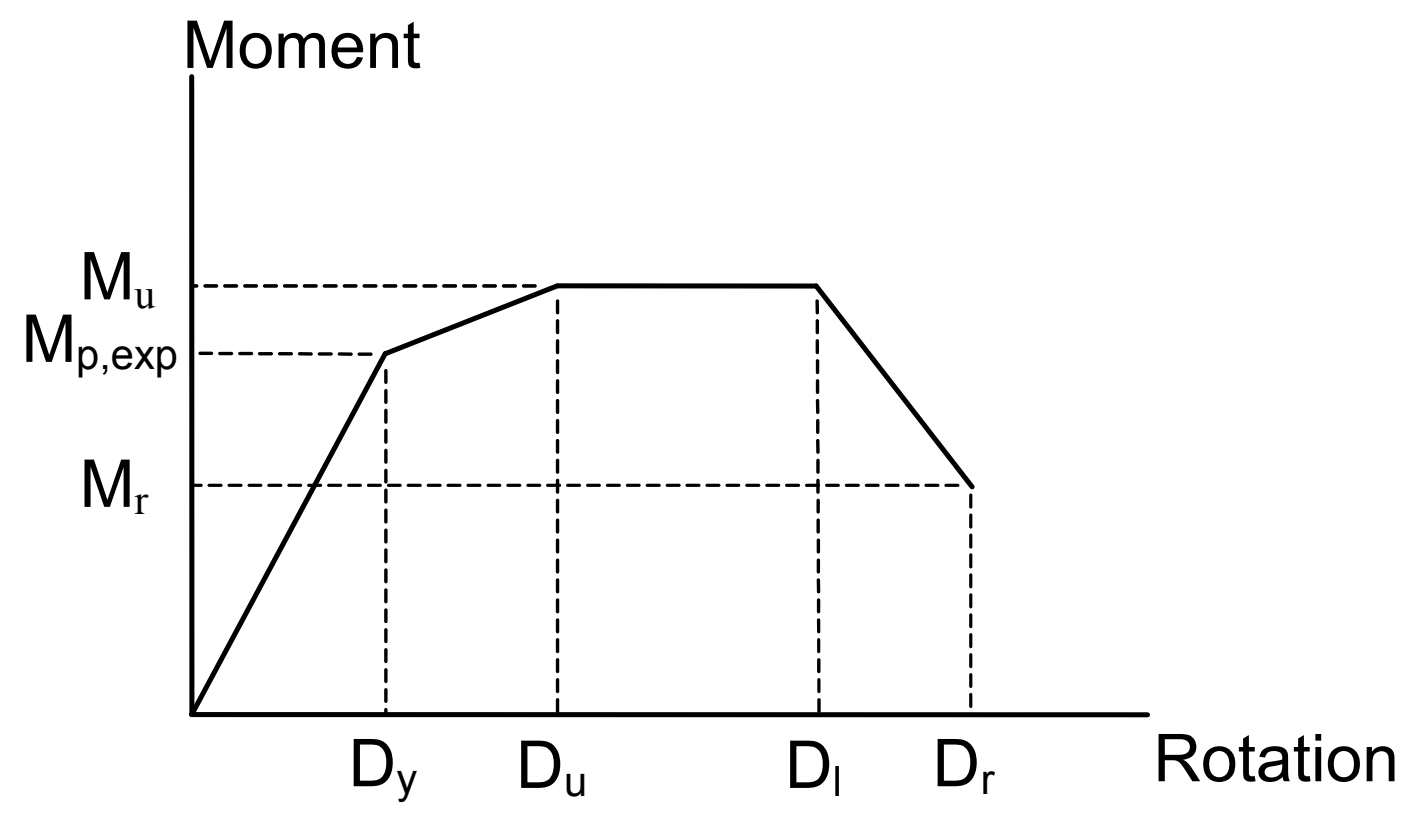

Fig. 24. Generalized moment-rotation relation for plastic hinges 


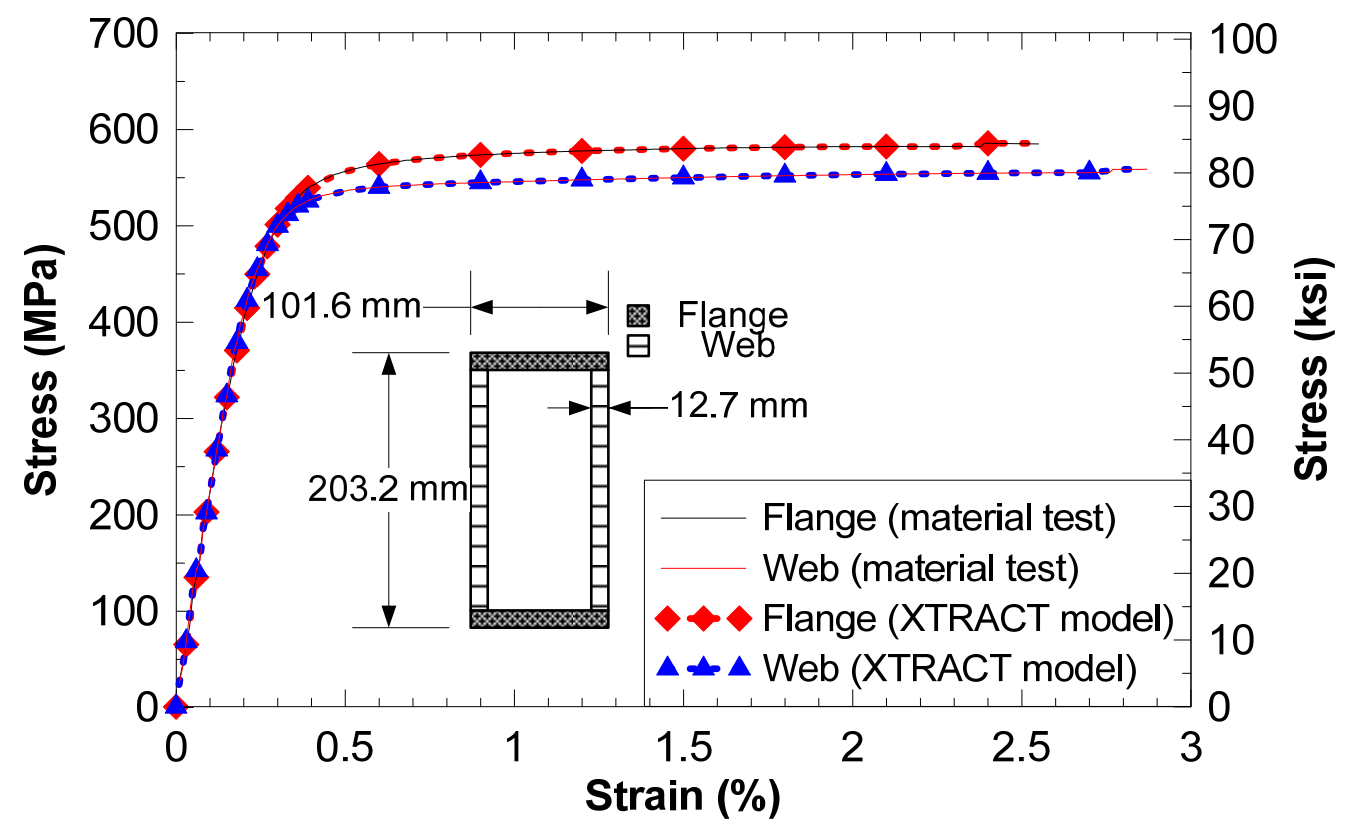

(a)

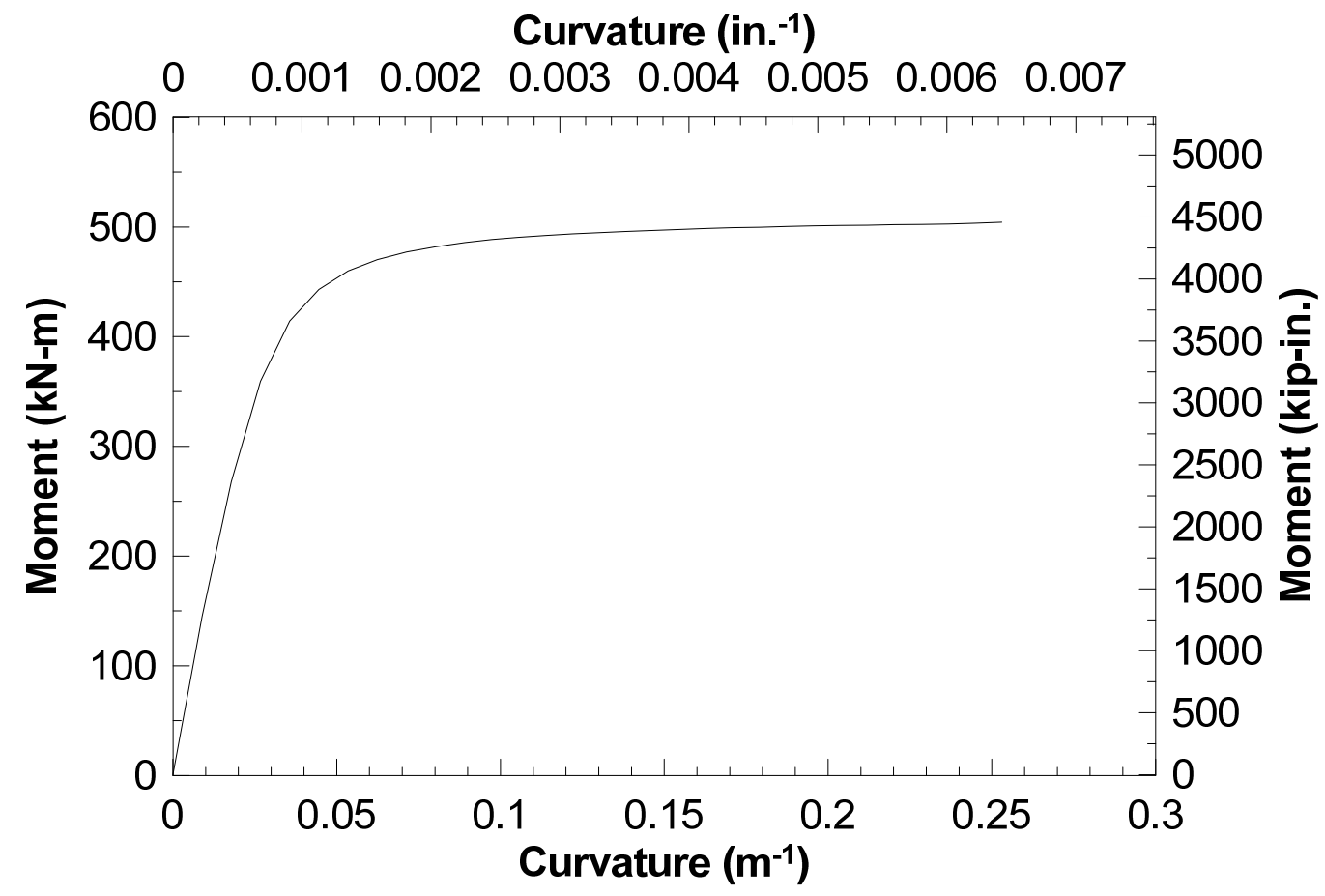

(b)

Fig. 25. XTRACT analysis and results: (a) material models based on material test results of flange and web of component test specimen, (b) moment curvature of component test specimen 